The Journal of Public Space

ISSN 2206-9658

2020 | Vol. 5 n. I

https://www.journalpublicspace.org

\title{
VIEWPOINT
}

\section{Placemaking in Lebanese Cities Hosting Displaced Communities}

\author{
Joana Dabaj, Riccardo Luca Conti \\ CatalyticAction, United Kingdom \\ info@catalyticaction.org
}

\begin{abstract}
CatalyticAction is a design studio and charity that works to empower communities through strategic and innovative community-led spatial interventions. They developed their architectural approach in the Lebanese context of displacement where the built environment and wellbeing are being constantly negotiated. Focusing on context specific educational spaces, they have created valuable impacts on the locality, on education, local economy, equality and wellbeing. The projects have been benefiting the most vulnerable groups including children, elderly and persons with disabilities. With this process of thinking and doing architecture, refugee and host communities co-design together and shape their shared built environment at this specific time of displacement, but also work towards a sustainable longer-term use of the spaces.
\end{abstract}

Keywords: participation, placemaking, displacement, built environment, child friendly spaces

To cite this article:

Dabaj, J., Conti, R. L. (2020). Placemaking in Lebanese Cities Hosting Displaced Communities, The Journal of Public Space, 5(I), 219-246, DOI I0.3289I/jps.v5iI.I259

This article has been peer reviewed and accepted for publication in The Journal of Public Space.

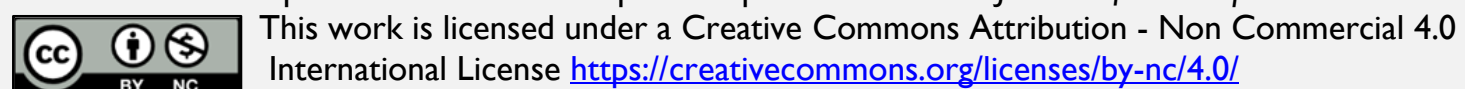




\section{Founding of CatalyticAction charity}

CatalyticAction (CA) started from the collective efforts of University College London alumni who had the goal of merging architecture, research and development planning skills with humanitarian work. The main question that they wanted to address is: How can design enhance current humanitarian practices in relation to the built environment? In 2014, with the Syrian refugee crisis unfolding in its $4^{\text {th }}$ year, Joana Dabaj and Riccardo Luca Conti, co-founders of CatalyticAction, who have a strong relationship to the Lebanese context, started in-depth research about the impact of the Syrian crisis on the neighbouring country of Lebanon, that was hosting at the time over I.I million Syrian refugees. Their interest was driven from the urge to act as built environment specialists to empower communities. They developed an architectural approach that seeks to challenge the passive provision of aid by moving towards a more just and inclusive approach to development, where individuals become active agents. They decided to name their team CatalyticAction because they believe that small changes can catalyse positive changes within communities. CatalyticAction is a charity registered in England and Wales, who kickstarted its mission with a project developed to address the lack of safe and recreational spaces for refugee children in Lebanon.

\section{A community-led approach}

CA works to empower communities through strategic and innovative community-led spatial interventions. They work with communities to deliver projects that can go on to sustain themselves, therefore catalysing community resilience. They adopt a participatory approach during all the phases of a project, therefore focusing on the process as much as on the quality of the final product. They use participatory methods as a tool to assess needs, implement solutions and monitor their impact.

In each project, CatalyticAction adopts three interconnected phases throughout the development of each project:

- Participatory planning

- Sustainable design

- Community-engaged construction

Their projects are creating valuable impacts on education, local economy, equality and well-being. The Charity has been mostly focusing on developing educational projects, (schools, playgrounds, public parks, etc.) as they have a great potential in their longterm impact.

Throughout all the phases of each project they focus on achieving 6 core values:

Value I: Revealing and enhancing community knowledge, culture, needs, visions, aspirations and skills.

Value 2: Transferring participatory tools for just decision-making processes.

Value 3: Transferring context-appropriate technology, skills and innovative design solutions.

Value 4: Generating livelihood opportunities.

Value 5: Supporting local businesses by prioritising the use of local materials and labour.

Value 6: Enabling equal engagement in decision-making processes among all community members. 

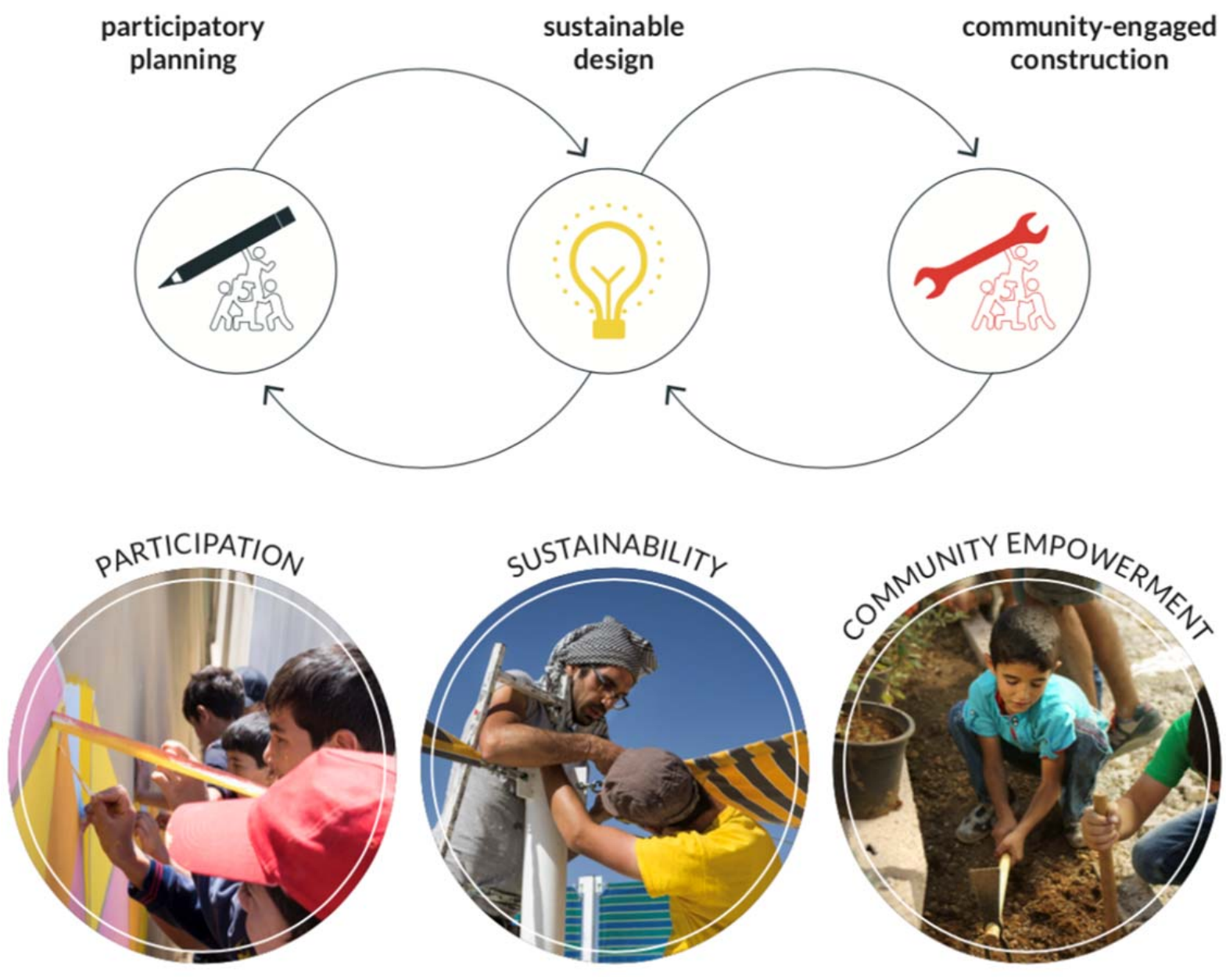

Figure I. CatalyticAction community-led approach

The participatory approach, combined with the Charity's values, have been proven to generate multiple positive outcomes. For example, using local materials and labour (value 5) together with transferring context-appropriate technology (value 3) can generate financial input for the local community, often supporting small businesses (value 4). This approach enables the local community to develop a sense of ownership towards what they have envisioned (value I) designed and built collectively (value 6). This approach also facilitates easier maintenance of the project as the community will have full knowledge of the project details (how it was built, where the materials were purchased, etc.), hence will be able to carry out maintenance without the need of external input. Community cohesion dynamics is also something that we have been able to generate through meaningful participatory methods (value 2).

CatalyticAction has been conducting participatory planning activities with different age groups, including children. To generate positive impact on child development, it is fundamental to engage children through participatory methodologies. As stated in the UNICEF Practical Guide for Developing Child Friendly Spaces 2009 meaningful participation gives voice to different sub-groups of children and enables the sense of local ownership 
that contribute to programme quality, equity and sustainability. Furthermore, as described in the Inter-Agency Network for Education in Emergency (INEE) Foundational Standards (Standard I Participation): "Community members participate actively, transparently, and without discrimination in analysis, planning, design, implementation, monitoring and evaluation of education responses."

CatalyticAction has developed a set of participatory planning toolkits that function as a starting point to conduct planning activities with community members. Nevertheless, the local context (culture, number of people involved, age group, etc.) is always considered when planning these activities in order to maximize their outcomes by reducing possible barriers to equal participation.

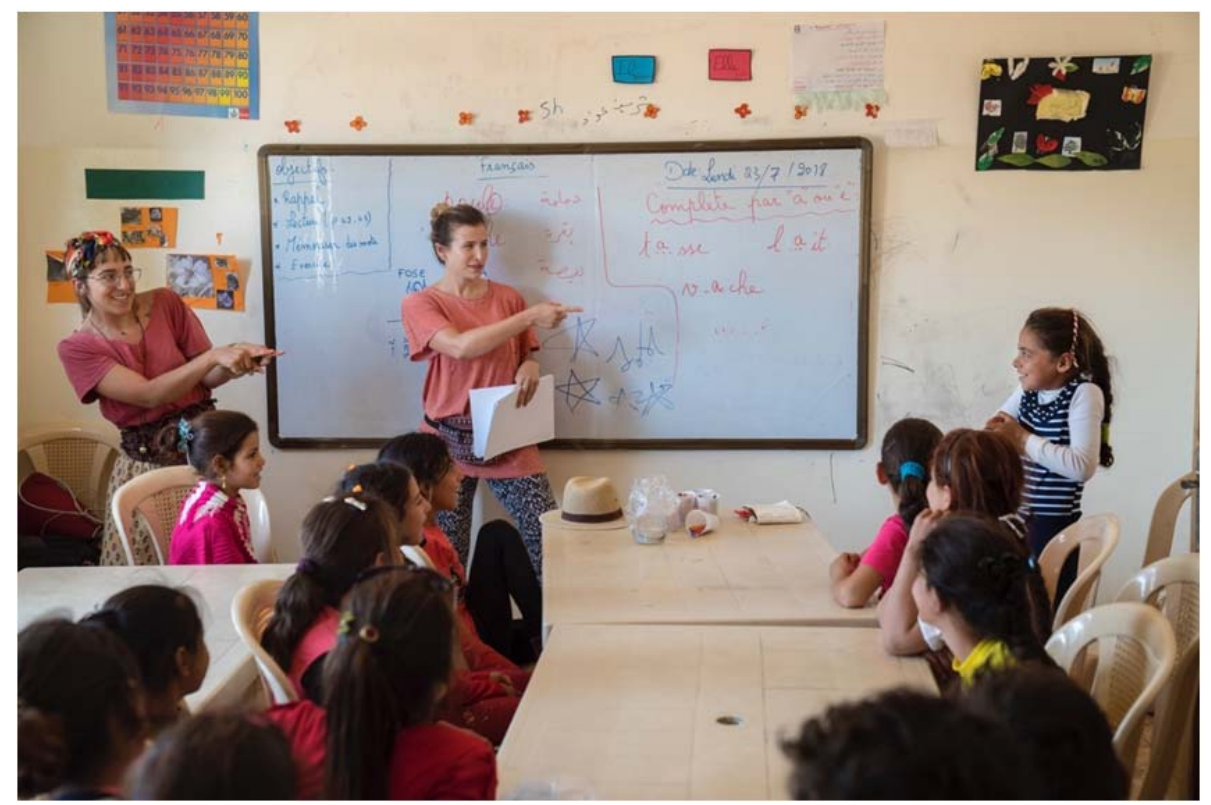

Figure 2. Children participatory activity in Bouday child friendly space, Baalbek, 20I7

\section{Playgrounds to cope and enhance community cohesion}

Since 20I I, the crisis in Syria has devastated lives, uprooted families from their homes forcing them to leave their country to find safety elsewhere. Syria's neighbouring country, Lebanon, has seen a sudden rise of population, hosting those who fled the war. Children are a particularly vulnerable group, and in Lebanon many of them live in substandard housing conditions where safe play spaces are scarce, if not absent. Many humanitarian actors responded to the most urgent needs, but little has been done to provide safe and stimulating learning environment for children. CA investigated Play in the Lebanese context of displacement. In 2015 as an initial strategy CA decided to intervene in existing schools equipping their courtyard with a model playground that allows different types of Play to happen including educational play opportunities. This model was named Ibtasem; a modular wooden structure tailored according to the availability of local materials and knowhow.

Article 3I of the UN convention for the Rights of Children states that we should recognise their rights to: "rest and leisure, to engage in play and recreational activities [...] to participate fully in cultural and artistic life". Ibtasem playground was designed through a 
participatory approach that involved children, teachers and different stakeholders who play a major role in providing education to vulnerable children in Lebanon. The result was a context specific playground that uses local materials and technologies. The play space that this playground offers is a spatial response to the specific needs identified during the participatory assessment phase, it provides active spaces, relaxing spaces and educational spaces. Ibtasem playground was designed as a temporary structure responding to the restricted 'spoken of regulations on what could be built for refugees in Lebanon. This pilot project did not only raise awareness on the importance of safe play spaces for children but most importantly it advocated for the prominence of participatory approach in design and building with children, which reveals the specific needs and aspirations of children rather than simply providing 'off-the-shelf play items. When children participate in the planning, design and implementation, they develop a sense of ownership towards the playground. They knew that their role was very important; "I am here to build the playground with you, so when I go back to Syria, I can build one myself" (Shahd, 5 years old student). Adding to this, volunteers worked hand in hand with the community to build the playground, learning from one another and crafting friendships. Enrico Porfido, volunteer from Italy reflected upon his experience: "I had the opportunity to join a real participatory process, involving local communities and mixing them up with our personal knowledge and experience. We built the process day by day, together."

With the success of the pilot playground project, other organizations recognized the validity of its design and impact and consequently replicated it; to date 5 playgrounds were built in Syria, France and Lebanon using the design principles of Ibtasem playground. "We have been inspired by your design and technical details, for the simple reason that the same materials and expertise were available in Syria" says Marya Zarif co-founder of Foundation Je Veux Jouer that replicated Ibtasem design prototype in two towns of Syria.

From temporary playground structures $\mathrm{CA}$ realised their valuable impact not only on child development but also on social relations between children, their teachers, parents and society. CatalyticAction realised this potential and moved to creating permanent playgrounds that benefit both refugee and host communities, with the aim to enhance community cohesion. In 2016, CA worked on Karantina Play garden, creating play spaces in a public park that was under renovation by the Beirut Municipality. CatalyticAction were commissioned, after winning a local design competition, to design and produce play items animating the Park through community participation. The aim of this intervention mainly was to create a meeting point for the diverse communities living in the neighborhood. With this project CA aimed at creating identity, creating places rather than spaces, and communities rather than entities. Karantina is a low-income neighborhood located in Al-Mudawwar district, North-East of Beirut. It is a mixed-use neighborhood where communities from different nationalities and ethno-religious backgrounds live. The Karantina neighborhood was cut through in the 1950s with a highway that detached it from the city. 


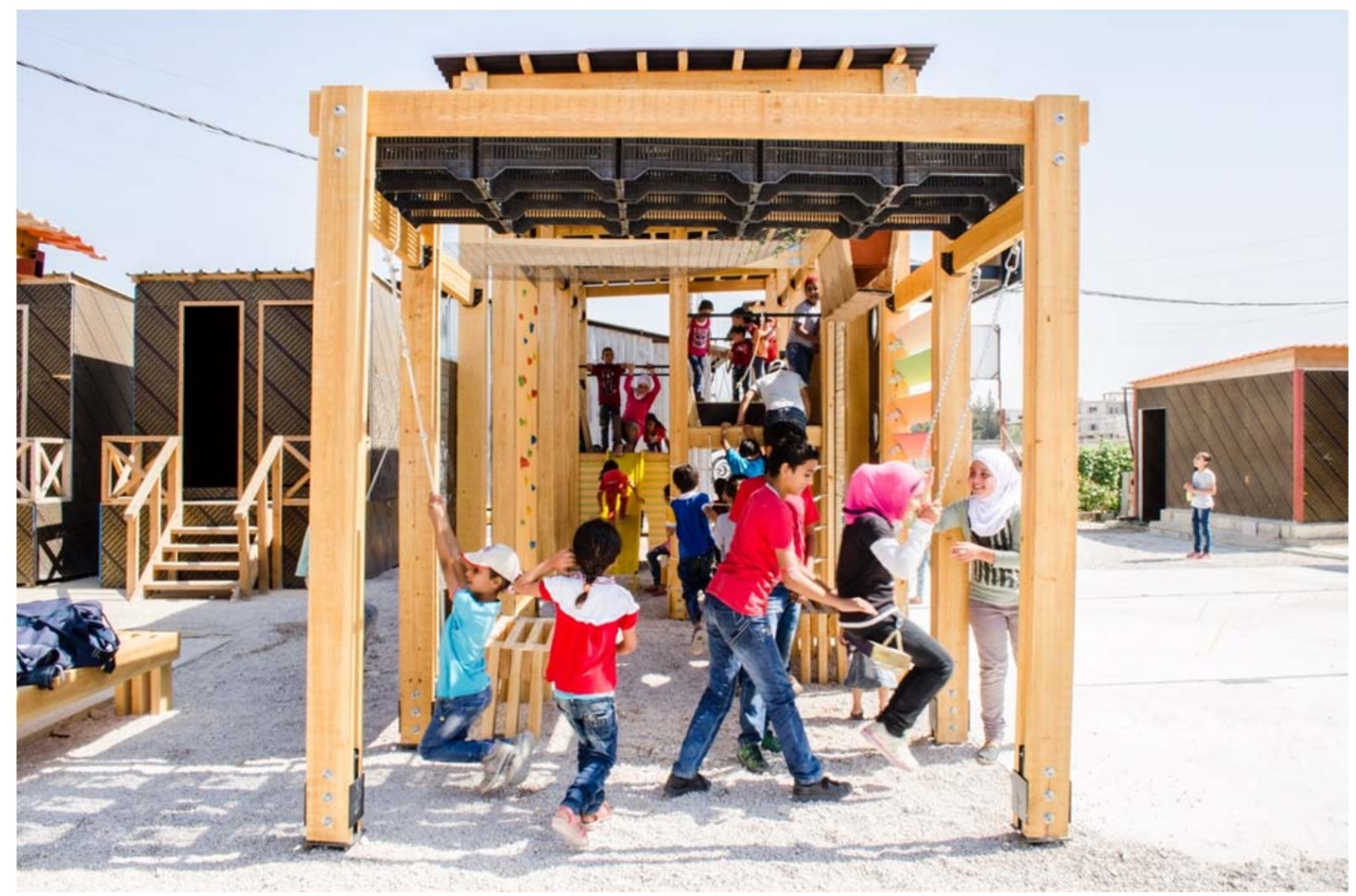

Figure 3. Ibtasem Playground, Bar Elias, 2015

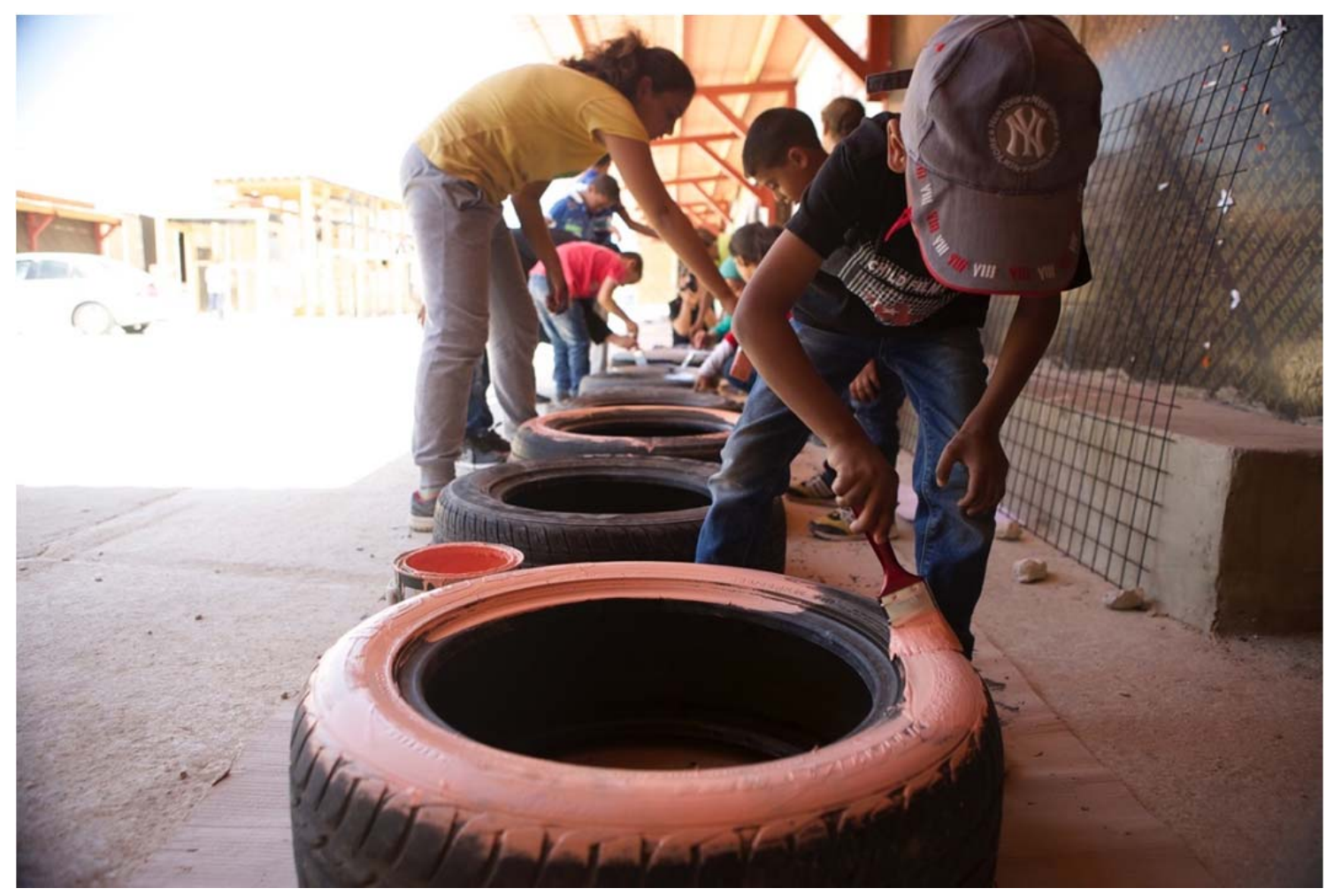

Figure 4. Children participating in painting activities during the playground implementation, Bar Elias, 2015 
During the Lebanese civil war, Karantina neighborhood suffered from intense political conflicts that left strong marks in the neighborhood social fabric. Being Beirut's gateway for people coming from Northern Lebanon, it represents a critical location of the constantly growing and overpopulated Lebanon capital. For several years it acted as the backyard of Beirut where only the most vulnerable populations found refuge, and where the city's undesirable services were located (slaughterhouse, heavy industries, etc.). Currently with the increase of rent in Beirut, Karantina area is attracting a new wave of art galleries, offices and recreational hubs that add to its socio-spatial complexity. The role of the Karantina Public Park was more important than ever.

The Park as a public space was never a meeting point for residents, a limited group of people only frequented it. According to parents in the area, the park has always been a hangout place for drug addicts and vandalism therefore their children were not allowed to play there. A group of interviewed elderly refused to visit the park because they weren't feeling safe there. This sense of isolation is accentuated by the presence of some of powerful members in the area who still have strong political influence on residents, as they did during the Lebanese civil war. The answer to the present challenge of creating resilient communities - which are able to respond and adapt to changing circumstances - lays in the quality and quantity of such links that participation will create and enhance. Recreational spaces, or more widely public spaces, play a fundamental role in the social life of communities. Public spaces have therefore the capacity to bring communities together by providing public facilities that can trigger or enhance communal activities. The Karantina Park represents a main opportunity space to resolve the conflict residing between the several community groups.

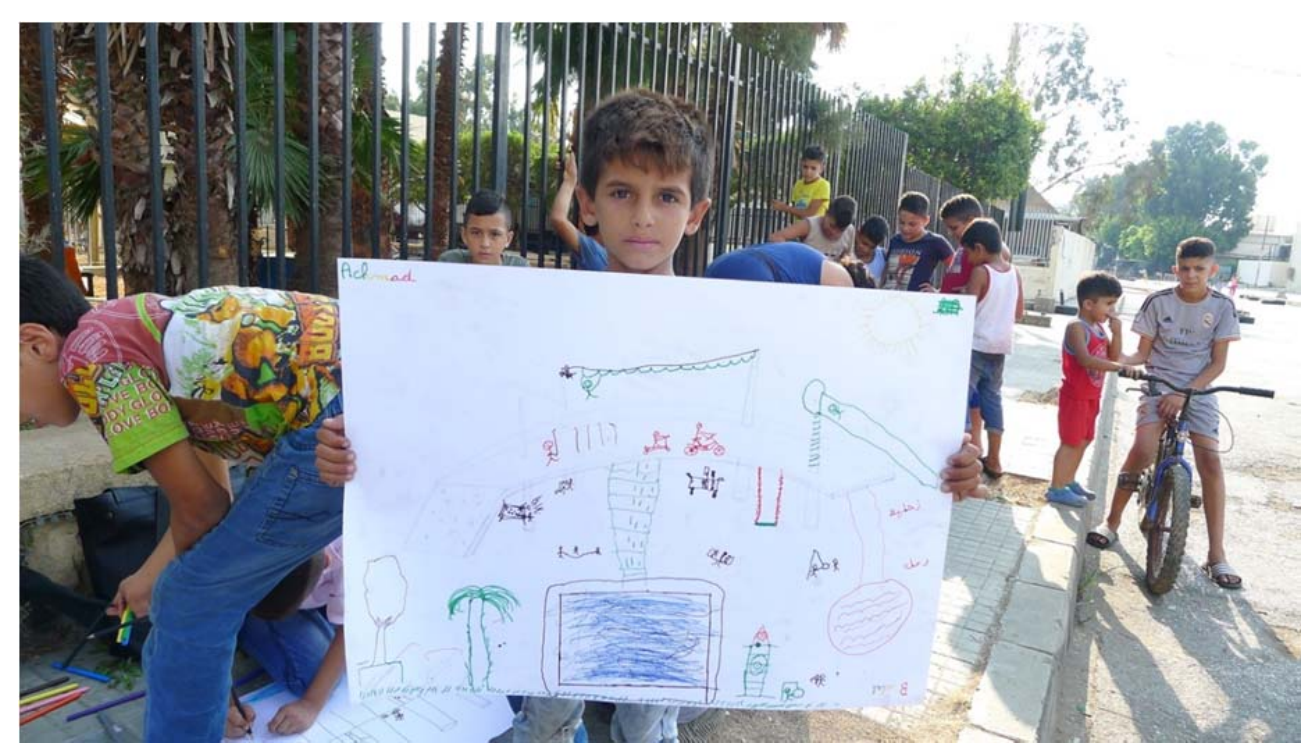

Figure 5. Children envisioning their new play garden, Karantina, 2016

The participatory engagement strategy for this project attempted to target all generations by arranging weekly workshops across the different communities. To accomplish this, CatalyticAction collaborated with three local groups: The Chain Effect, Recycle Lebanon and Urban pins. The introductory workshops carried out by 
CatalyticAction included a series of drawing and model making to introduce the children to the project and engage them in the initial design process. As bicycles are a core element in the neighborhood, especially among children, the workshops with the Chain Effect aimed at enhancing this characteristic, raising awareness about the role of cycling, and looking at the potential of bicycles beyond movement, sport and leisure. The intervention was stretched out beyond the fence, with a mural in front of the entrance painted with residents of the neighborhood, the aim of the mural was to raise awareness on bicycle use while adding a colorful landmark. The workshops carried out with Recycle Lebanon aimed to teach the children about the importance of the environment, this included sorting collected garbage from the neighborhood. Noticing that scavenger hunting for leftover materials to build primitive structures is a common activity among the children of the neighborhood, an idea developed with Urban Pins to teach the children how to use these leftovers to make musical instruments. A concluding workshop saw the implementation of a second mural; after seeing the mural at the park entrance, residents living a bit further from the park requested to have a mural in their street as well, so in order to create a sense of equality amongst the several communities the intervention reached to this further location, where children, youth and adults painted their colored the wide factory wall.

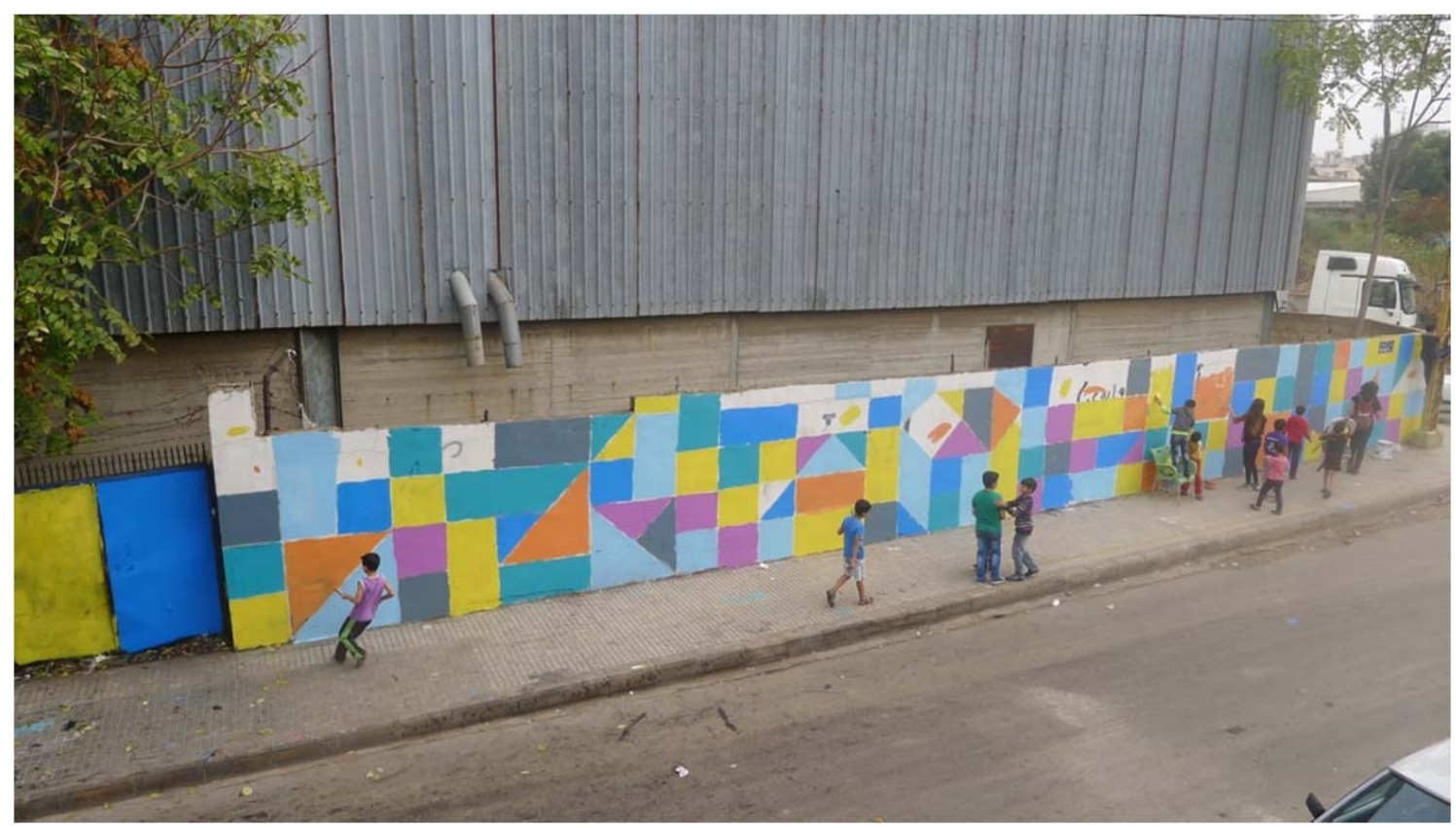

Figure 6. Children and youth paint the mural on the factory wall, Karantina, 2016 


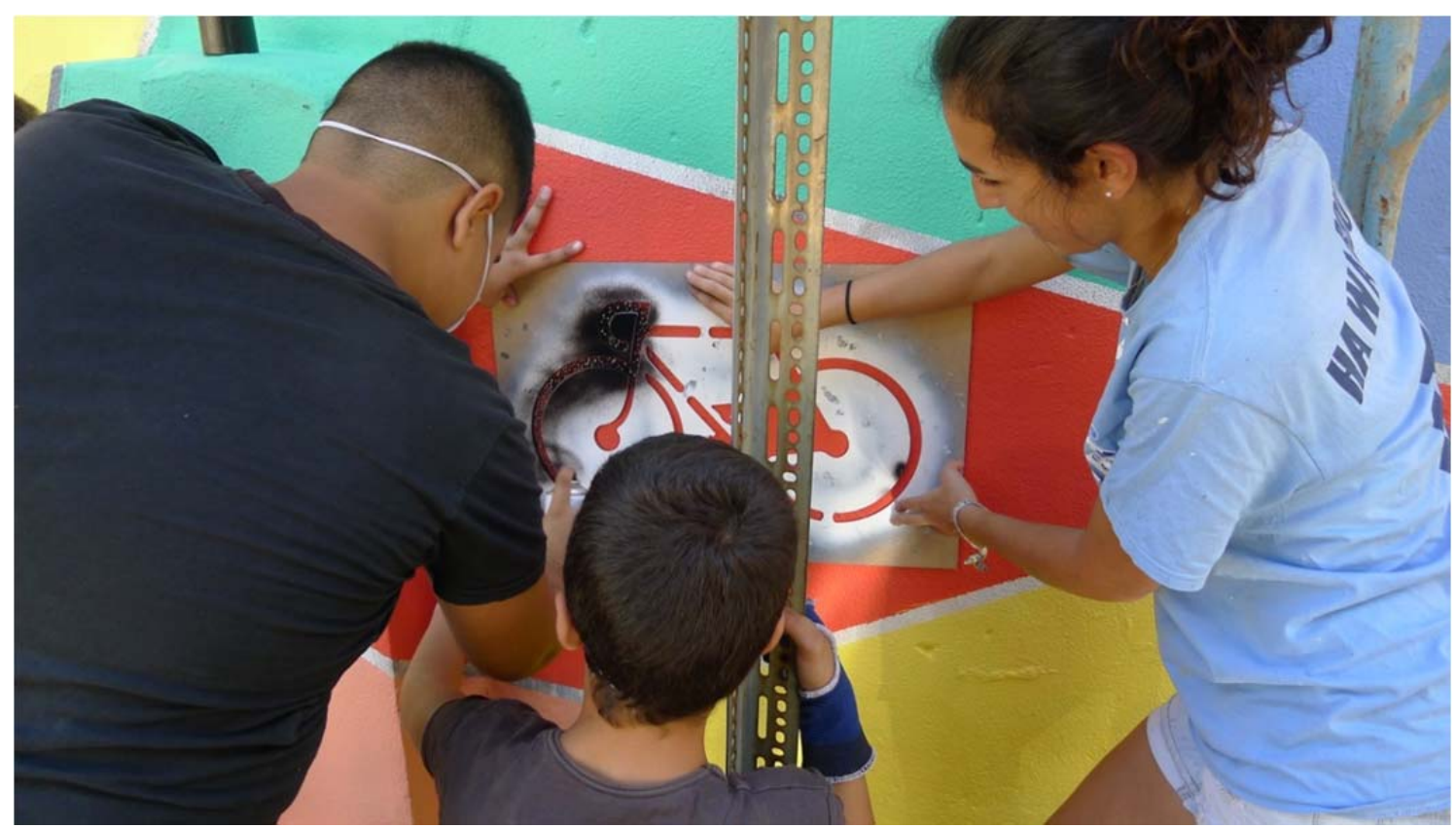

Figure 7. Children and youth paint the bicycle awareness mural at the entrance of the park, Karantina, 2016

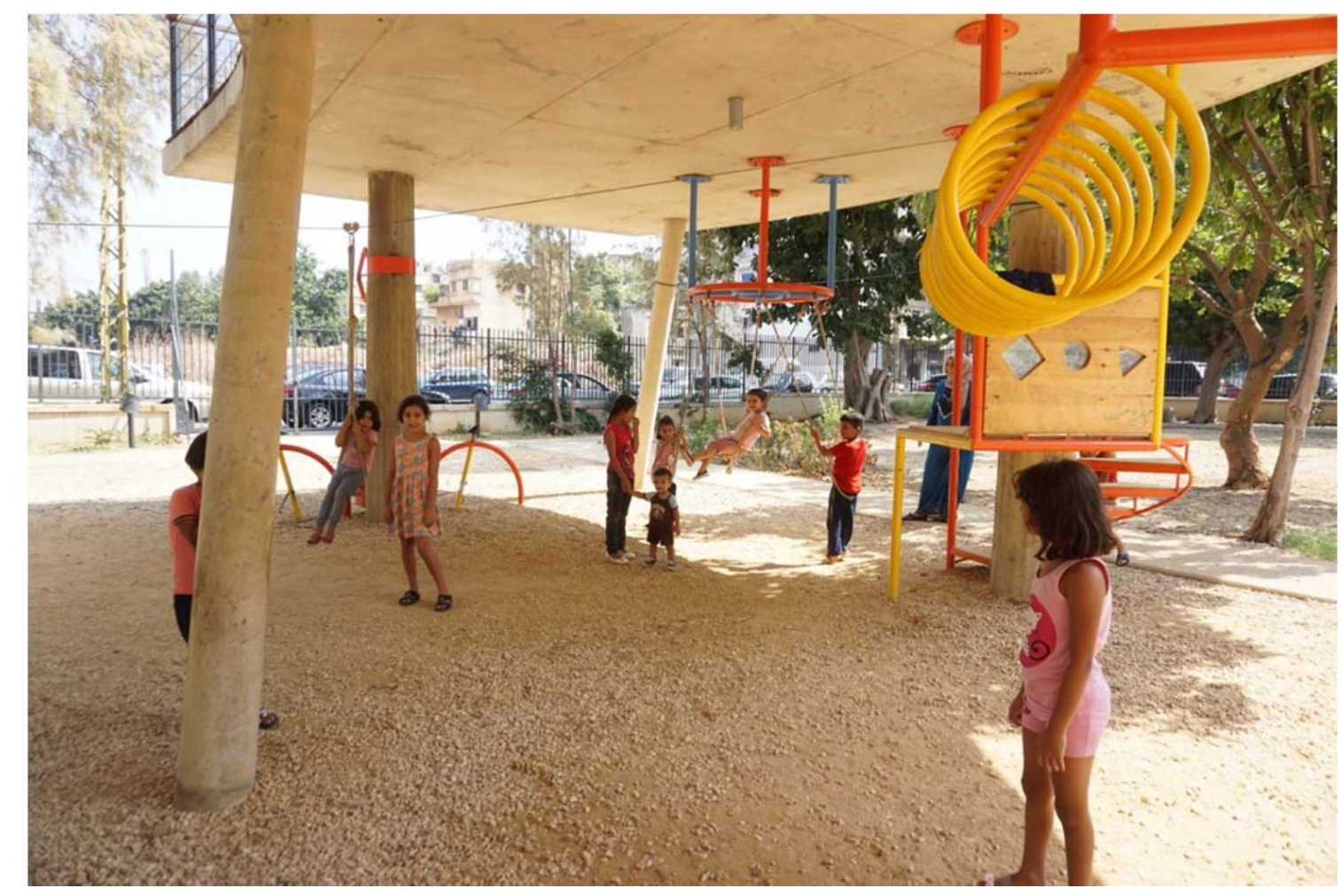

Figure 8. Karantina Play garden, Karantina, 2018

After working within existing schools and creating places of encounter in the public realm, in 2017, CA designed and implemented Basma Playground in Ghazze, West Bekaa, 
Lebanon, in a school but serving the public as well. This project was implemented in partnership with the Social Support Society (SSS) NGO, an organisation that provides education for Syrian refugee students as part of their Relief and Educational Assistance project. The Social Support Society partnered with Al-Maqassed school that was set up in 1950 to provide education for vulnerable Lebanese. The school simply extended its operating hours in order to create a second shift for Syrian refugee children, while the morning shift remained for Lebanese. As part of their partnership, the SSS refurbishes and upgrades the school premises, Basma playground constituted one of those needed improvements. The playground space aimed at providing safe play spaces for all age groups attending the school, Syrian and Lebanese, including toddlers and young children. The playground was designed through a participatory process that engaged the students, teachers and other school staff as well as the municipality. The playground offers spaces for structured play, free play, imaginative play, as well as spaces for outdoor classes and multiple relaxing spaces. Basma playground is also open to the public where residents of town can access it during weekends and public holidays.

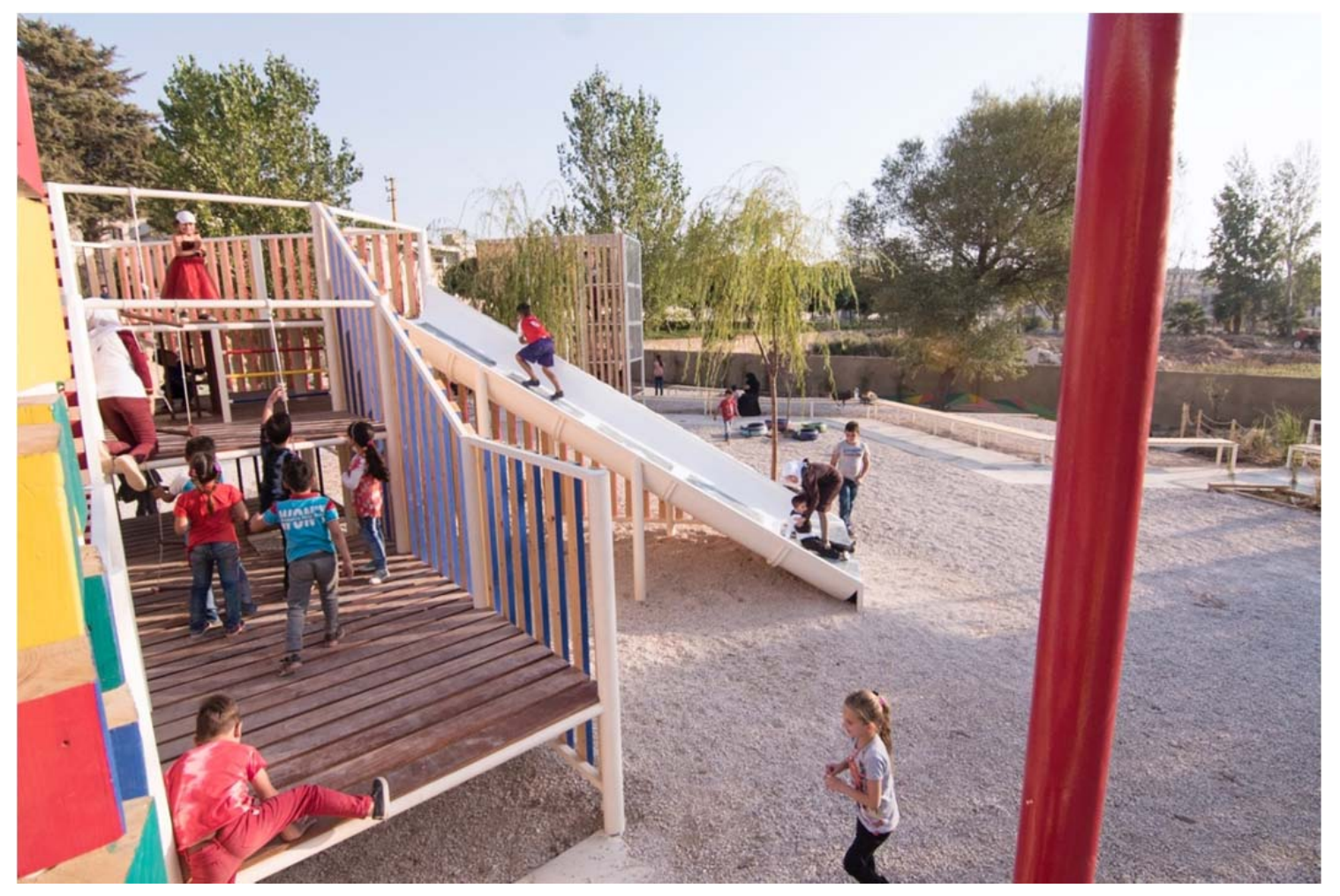

Figure 9. Basma Playground, Ghazze, 2017

The playground design is a permanent recreational and educational space for the school and the town of Ghazze. The choice of the materiality of the playground design was affected by CA's values, such as: supporting local businesses by prioritizing the use of local materials and labour. A skilled welder shop from Ghazze worked with CA team on the realization of the project, this did not only boost the local economy but also through such process the local welder experienced with new design prototypes, learning new skills and creating something new for his own town that he was proud of. 
The quality of the steel work was exceptional in this project, proving that it is important to do a market research of available skillset and knowhow during the design phase.

While purchasing local materials CA team and volunteers met the local residents living in Ghazze, Lebanese, Syrians and Palestinians. One of the most memorable experience was when a young man from the town was inspired by the participatory implementation that involved International and Lebanese volunteers, that he decided to volunteer himself. $\mathrm{He}$ is a Syrian refugee living in Ghazze, he worked at the hardware store where CA bought some building material, he used to join the team on site after his work shift and on his days off, he worked hand in hand with the team to complete the project. He was also excited to learn and practice English language with the International volunteers. When asked why he decided to volunteer, he answered that "this playground has such great positive impact on the lives of Syrian children. Drawing a smile on their face, after all the suffering they have been through, means the world to me."

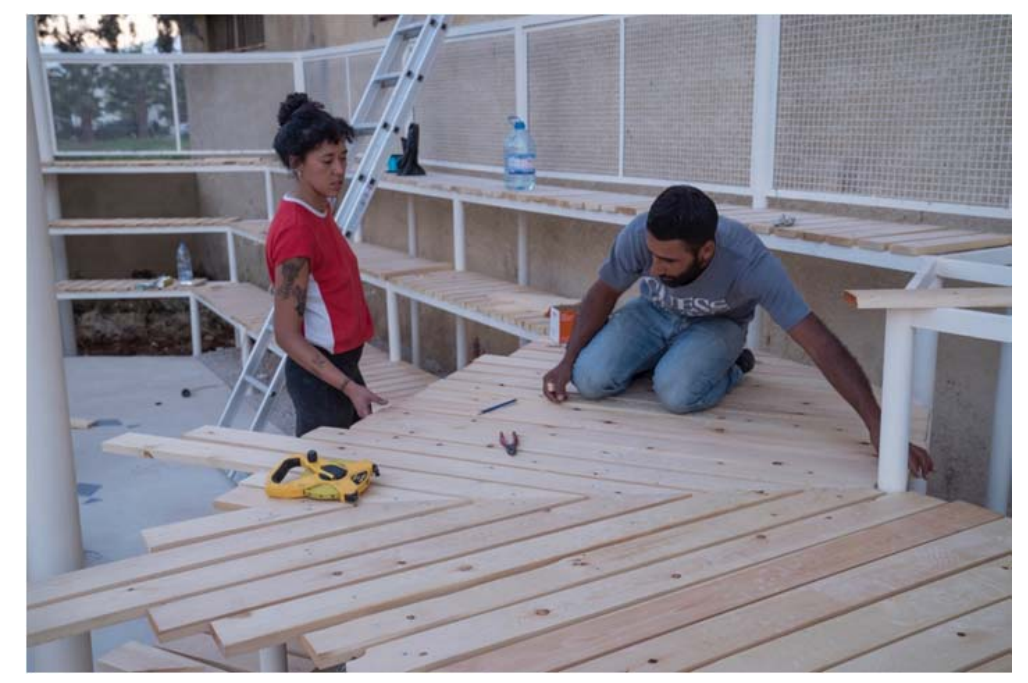

Figure 10. Volunteers from Chile and Ghazze join hands to build the amphitheatre, Ghazze, 2017

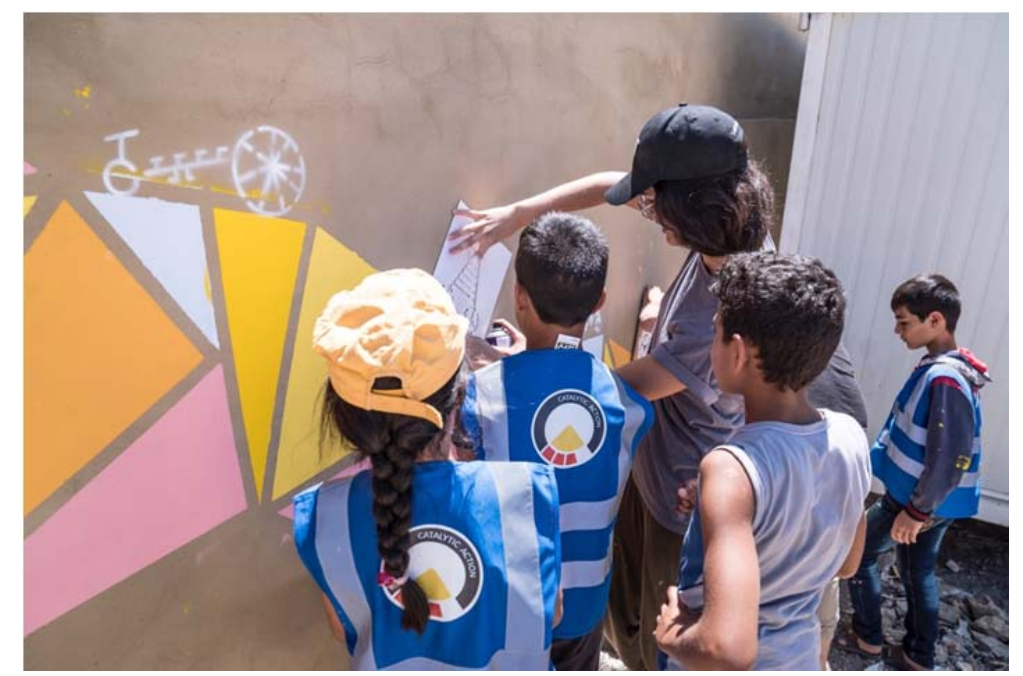

Figure II. Children paint the walls of their school entrance, Ghazze, 2017 


\section{Inclusive placemaking}

Inclusive public spaces in Lebanon are scarce and often not considered a priority in the public works plans of local municipalities. Inclusive public spaces are spaces that are accessible by everyone, including women, children, elderly and people with disabilities. Vulnerable groups such as children with disabilities greatly benefit from using accessible and inclusive public spaces where they have the opportunity to play with their parents, relatives and friends. In Lebanon, these spaces would represent a medium for equality in a country where social segregation and tension are strongly present as presented in the Karantina Public garden. Yet, most public spaces do not offer safe and welcoming spaces for everyone. As a result, vulnerable groups often struggle to find incentive to use public spaces either because of physical barriers or psychological (i.e. women do not feel safe). In addition to this, there is also a widespread misconception that inclusive playgrounds are very expensive as play items need to be imported from abroad, which keeps many municipalities, NGOs, schools, etc. from investing or even considering to implement such interventions. The inclusive parks project aims to raise awareness on the importance of inclusive public spaces by adopting a practical approach, engaging and empowering local community members and different municipalities in the design of an innovative inclusive public space. The project aims to practically demonstrate that inclusive spaces can be done by using local materials and skills, hence benefiting the local economy in the process and empowering local communities.

The project was implemented in 2019 in 3 locations of Lebanon: Arsal, Hermel and Barja, it is in partnership with Terre Des Hommes Italy and UNICEF under the action "Child protection support for the most vulnerable children of North Bekaa and Mount Lebanon". The sites of interventions were identified by Terre des Hommes Italy in close collaboration with the local municipalities. Existing public parks were chosen as the ideal location for these interventions, as the parks were already used by families and known within the local communities. This gave an added value to the projects, as through the implementation of inclusive spaces existing social dynamics were enhanced. All design interventions share the same design objective of creating accessible spaces that allow children of all abilities to come together and play. The spaces are also designed to allow different age groups to play simultaneously. Spaces for parents (i.e. shaded seating area) were also allocated as this was identified as an important element that would allow parents and children to visit these public spaces.

CatalyticAction's process was adopted for the design and implementation of these spaces. Participatory design activities were conducted engaging people from different nationalities, genders and age groups (children, youth and parents). CA also conducted participatory activities with persons with disabilities in collaboration with the local organisation Balsam. This was particularly useful to understand their specific needs and aspirations in relation to public spaces.

Arsal is a border town in the North East located in the Baalbek district of BaalbekHermel governorate, Lebanon. Arsal hosts 32,606 registered Syrian refugees (UNHCR, 2018 ) the highest in the governorate, according to the mayor of Arsal, Bassel AlHoujairi, the number of Syrian refugees in Arsal reached 120,000, in a town that originally had 30,000 residents. Arsal was "a base for anti-regime fighters, a transshipment point for explosive devices" and a threat for Lebanon's security apparatus (International Crisis group, 2016). "In 2014 a battle between Syrian Jihaidis and the Lebanese army put Arsal on the map as a national threat in the minds of many 
Lebanese" (ibid.). The mayor of Arsal shared his relief that Arsal insecure and threatening days are over (2019) and how with such projects enhancing social relations that the whole country will look into a brighter future.

The design of Arsal child friendly space focused on two main elements, making the public space accessible and creating an inclusive playground. The design concept can be summarised in two spatial components: 'playful ramp' and 'playful stations'. The 'playful ramp' offers a play experience for all children, while at the same time it allows persons on wheelchair to access the upper level of the existing public space. The 'playful stations' offer different play experiences such as active play, imaginative play and sensory play. The 'playful stations' mimic the landscape of Arsal, which is mostly characterised by scattered buildings placed on a mountainous scenery. These 'playful stations' have coloured sloped roofs which appear to play with the mountains slopes and colours. The park was also equipped with an accessible toilet, which was built by transforming the existing non-accessible bathrooms in a fully accessible one.

Fayad, the contractor representative in charge of the construction of the project, was extremely proud of to have such innovative project in his home town. All the laborers who worked on the project were from Arsal, they have learned new skills especially how play items can be locally manufactured. Fayad, who is also an architect learned a lot from this project especially on what design can do for play spaces for children.

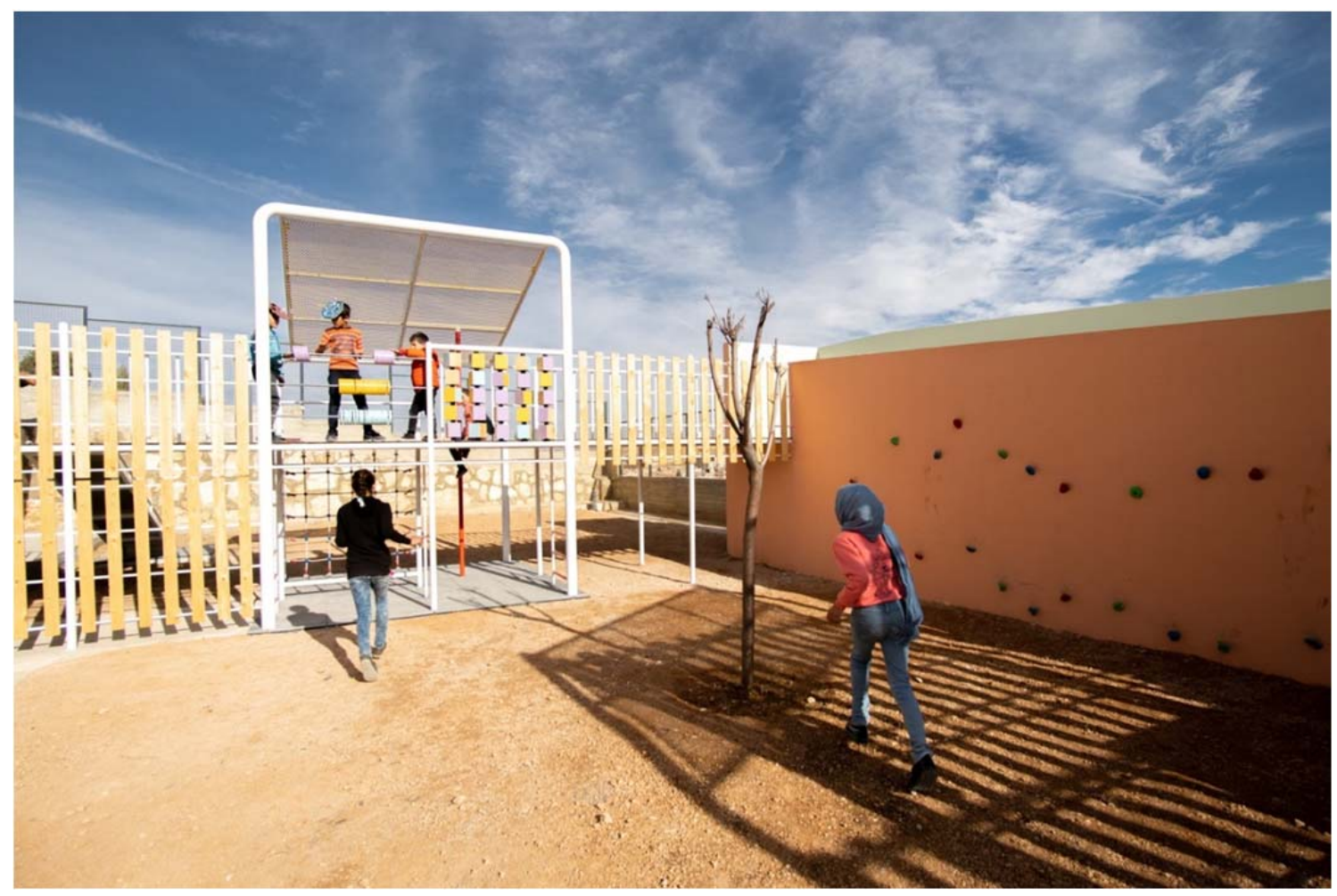

Figure 12. Children enjoy different types of play, Arsal, 2019 


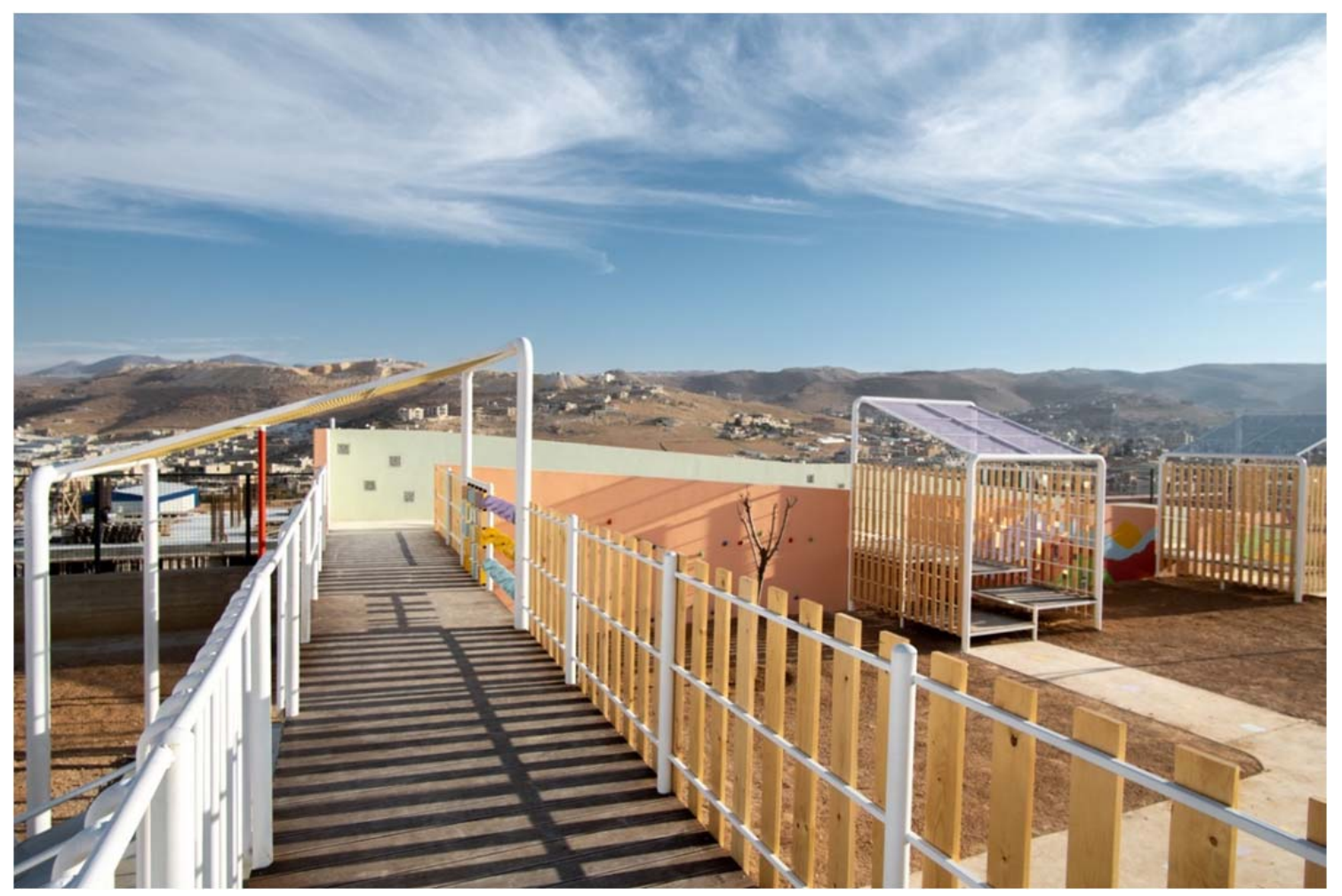

Figure 13. The access ramp and the natural surrounding guided the design, Arsal, 2019

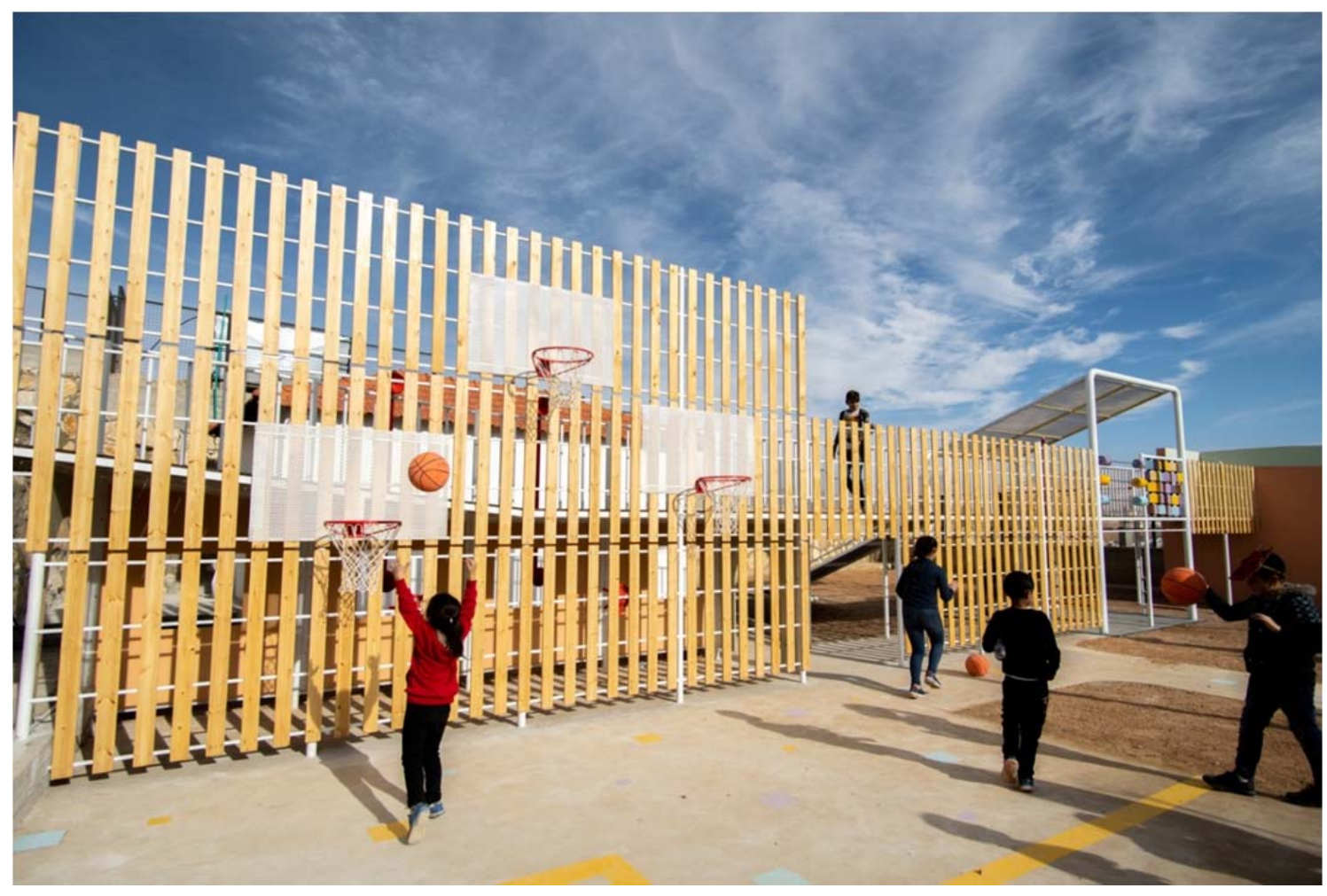

Figure 14. Children, both boys and girls, play basketball, Arsal, 2019 


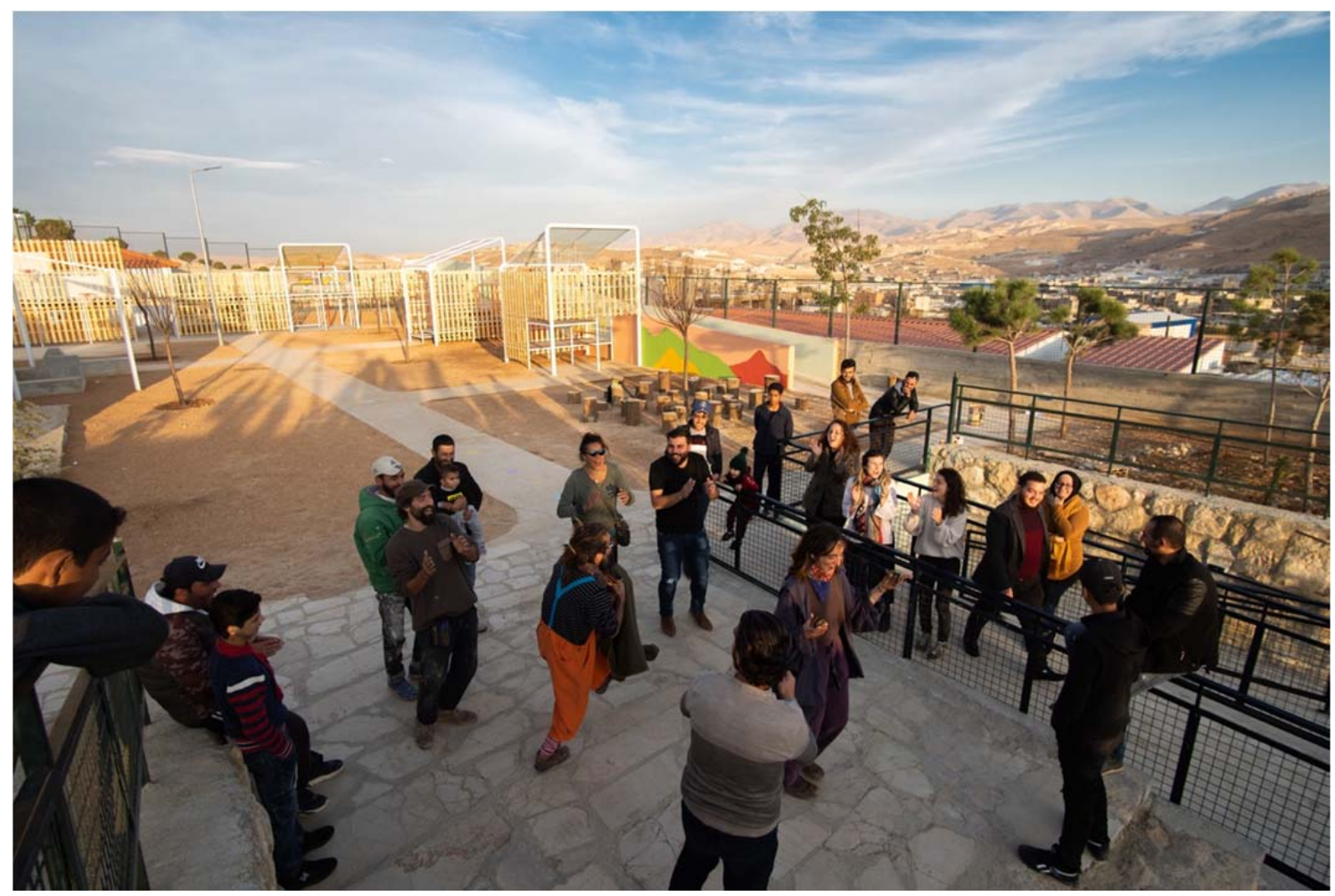

Figure 15. Architects, contractor's team and animators enjoying this new friendship and place, Arsal, 2019

Arsal's Mayor expressed how this new public space is very educational and it represents a safe space for child development. He said that through the games provided children are happy and they also learn new skills. He also spoke about how participation, equality and friendship are enhanced in such public space and that this is something that is missing in Lebanon. According to him having more spaces like this would help to resolve conflicts. He pointed out that you can see people claiming this type of spaces now during the revolution. In fact, in many cities people are taking over the streets making them public squares where ideas are shared. He then said that when children learn how to use a space together, they learn how to respect each other which is brings hope to a bright future. He added that mutual respect among the different groups living in Lebanon is something that is really needed at this point in history. Hermel is a town located in Baalbek-Hermel governorate of Lebanon, it hosts 6, 100 registered Syrian refugees (UNHCR, 20I8). The public space chosen as a site of intervention is the oldest park in the town, known for its big trees and greenery. During the participatory assessment, it was fascinating how the parents shared memories of play in this space and were excited that this project will activate the space again allowing their children to create new memories there as well. The design for Hermel child friendly space focused on maintaining the natural character of the space, while introducing play spaces and relaxing spaces for everyone. The site was divided in three main areas: family area, playground and football court. These areas are connected to each other with a new concrete path, which allows accessibility to all play facilities and spaces. Families use the 'family area' for picnics, which is a social and leisure activity that the intervention aimed at enhancing by providing permanent tables and chairs that embrace the natural 
elements of the parks. In addition to this, play facilities were placed between tables so that toddlers and young children are able to play near their parents. The playground includes three play stations, each one providing different games and experiences of play such as active play, imaginative play and sensory play. The football court was set up on an existing space where children played football. Again, through the intervention existing uses and social dynamics were enhanced.

A young Syrian girl playing for the first time in the park, also participated in the participatory design activities. She was very happy to see that the park turned out to be even better than what she had envisioned. She said she will ask her parents to bring her to play there again. This is very empowering to young children, to learn that their role was important. A concluding set of activities was planned to finalize the space, where children painted together colorful animal figures. Ahmad, the contractor representative in charge of the construction, was very appreciative of the efforts that engaged the locals of his town to realize this project. All the hired workers were from Hermel. He brought his wife and newly born child to show them the project he was a part of; the family enjoyed their day at the park.

Barja is a coastal town located in the Chouf district of Mount Lebanon Governorate. It hosts 7,126 registered Syrian refugees (UNHCR, 2016), the highest number in Mount Lebanon Governorate, and considered one of the most vulnerable localities. The site of intervention chosen for the child friendly space is a section of a parking area adjacent to an existing public space completed in 2016 . The project saw the transformation of the parking into a stimulating child friendly space that links to the existing public park.

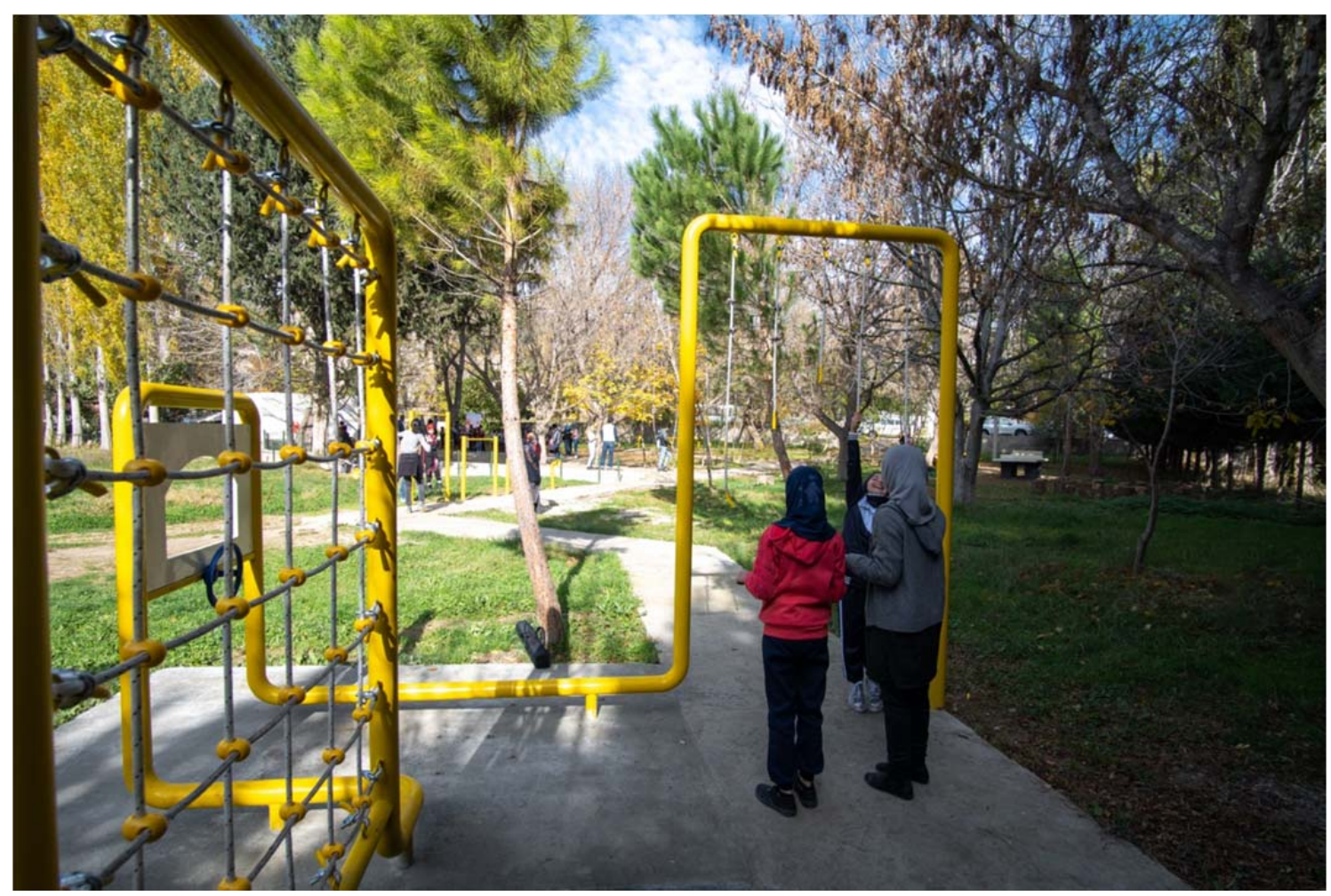

Figure 16. Children enjoy the musical games, Hermel, 2019 


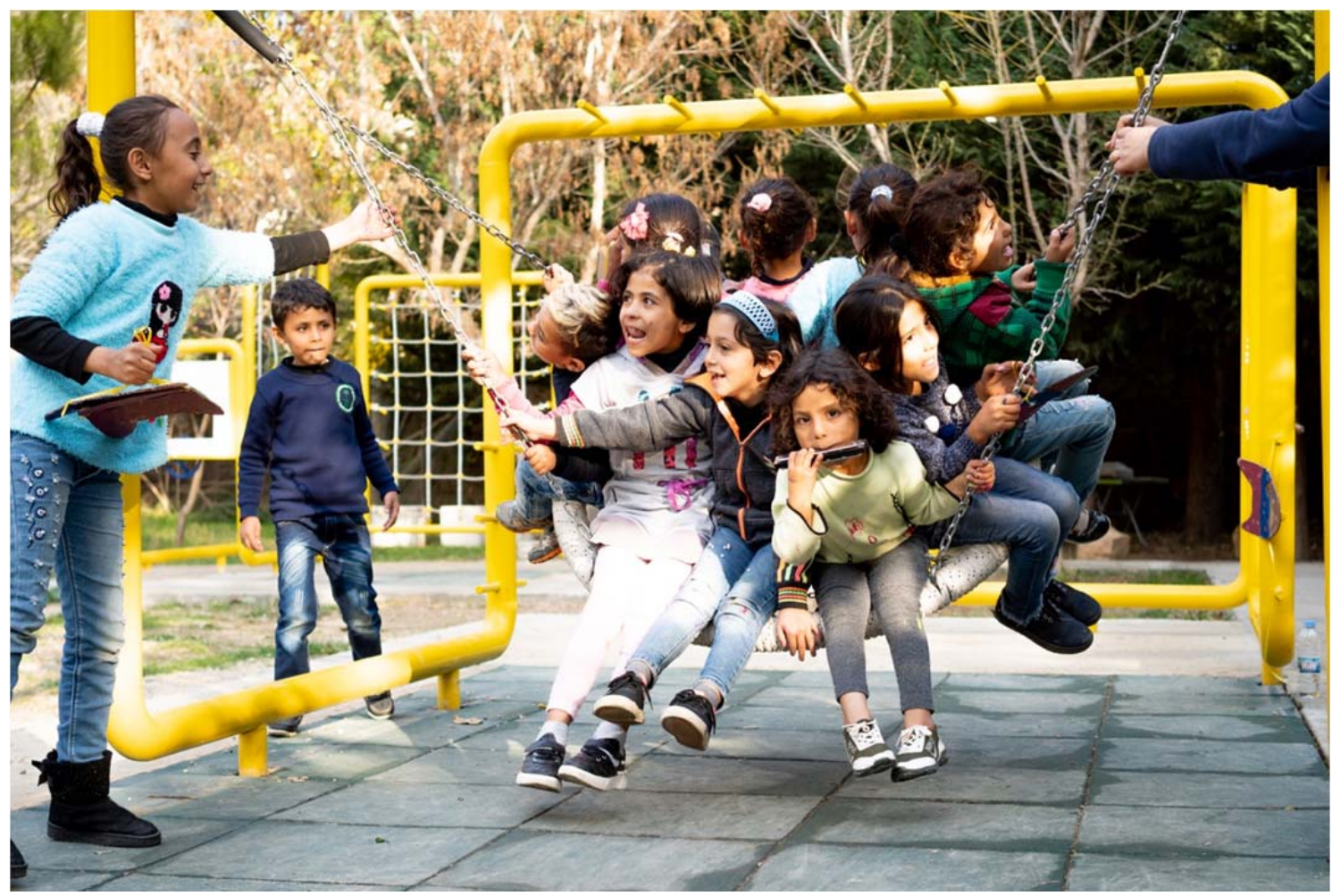

Figure 17. Nine children enjoying the nest swing together, Hermel, 2019

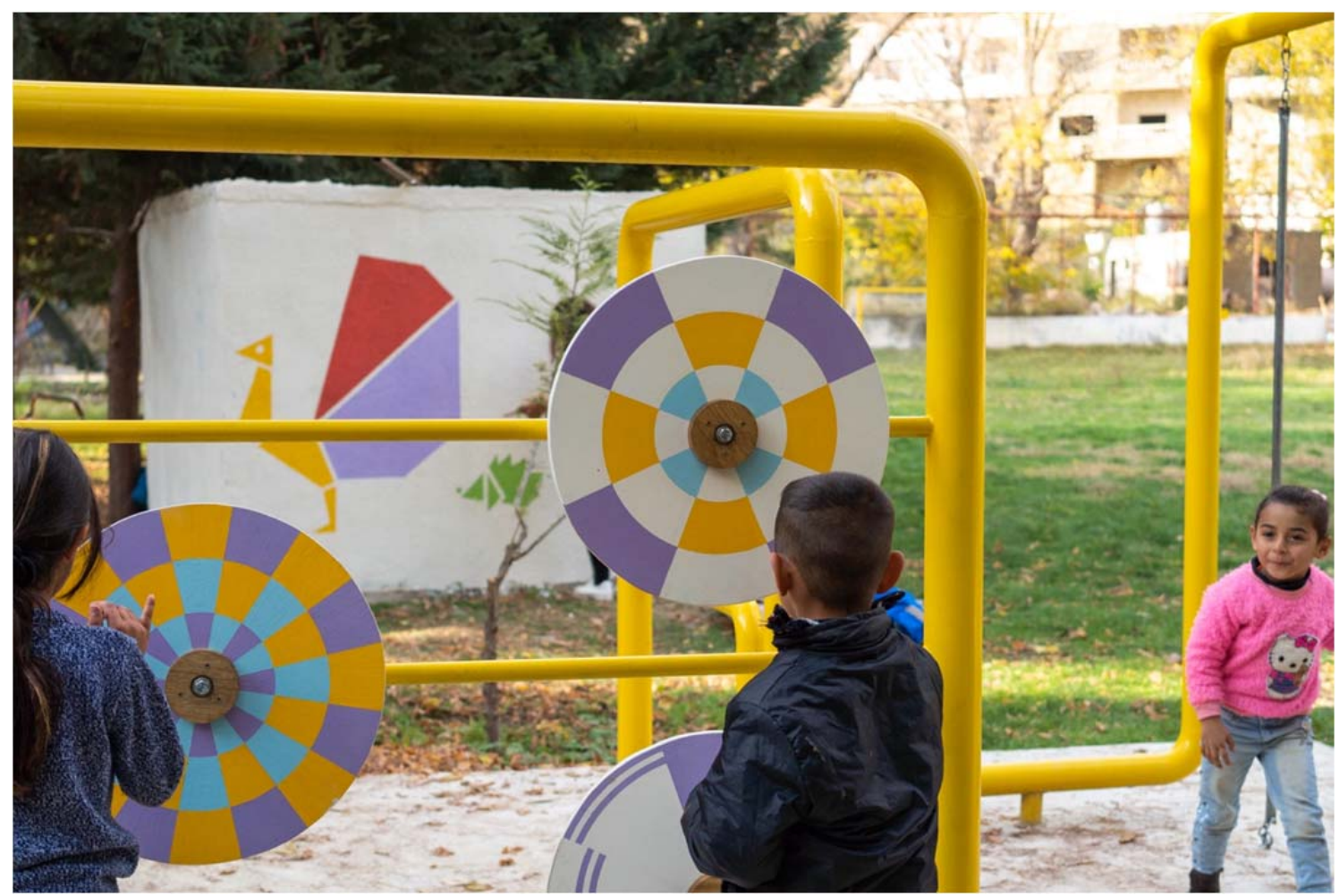

Figure 18. Children fascinated by the spinning circles optical illusions, Hermel, 2019 


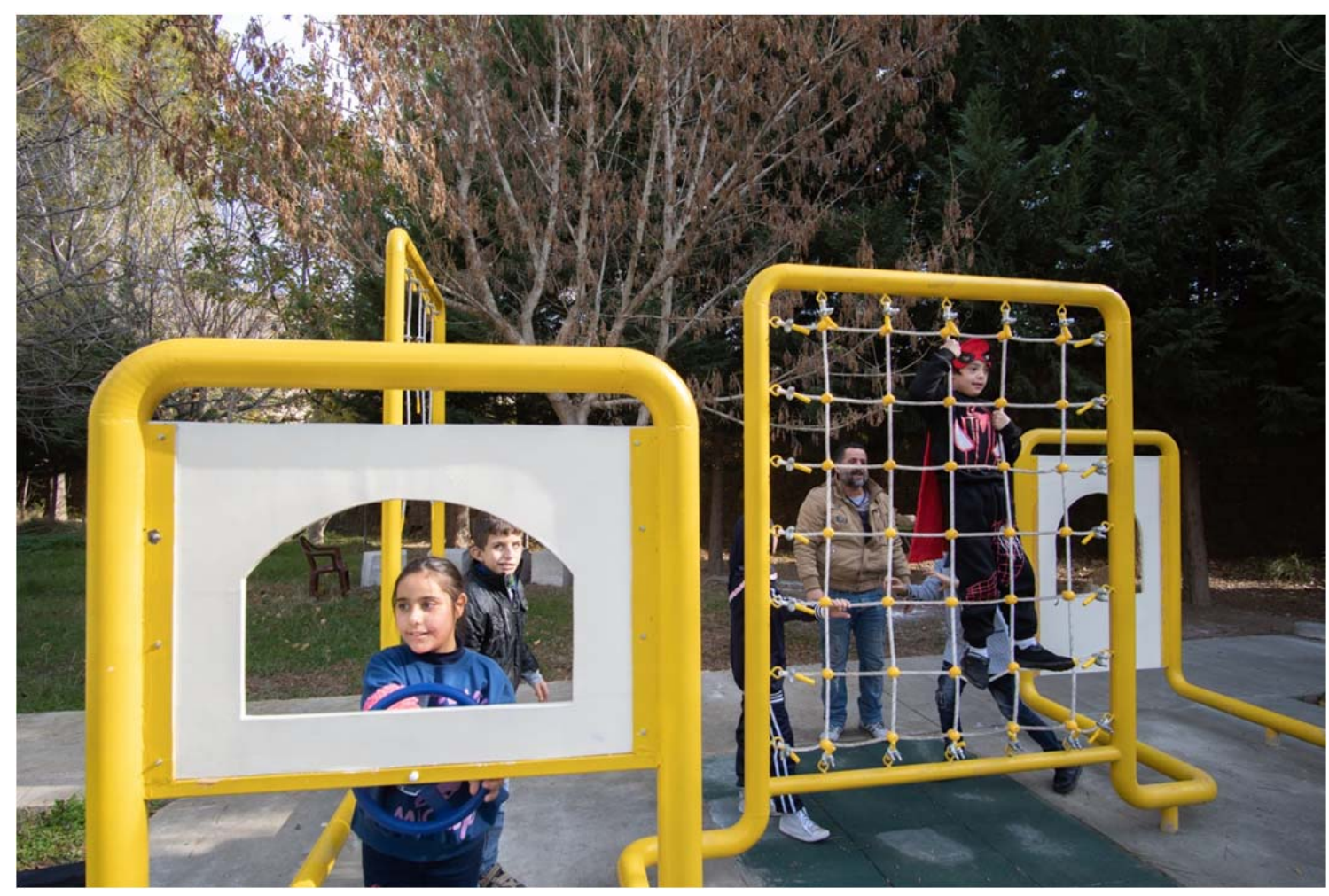

Figure 19. The inclusive play stations allow children of all abilities to play together, Hermel, 2019

The design in Barja CFS focused on creating a compact, accessible, dynamic and stimulating play space. The sea view was an important element that greatly shaped the design. The playground is therefore developed along an accessible ramp which leads to a raised platform that points towards the sea, hence offering a clear and peaceful view of the sea. Different games were incorporated in the playground structure, which offer different play experiences such as active play, imaginative play and sensory play. The games are placed in a way to generate multiple opportunities for inclusive play. The playground structure has a distinctive shape and has been built by using steel and timber as main materials.

The mayor of Barja, Raymond Hamieh, showed interest in doing similar projects in other public spaces in Barja. He really appreciated the educational aspect of the playground spaces, which is a main factor for him to have such space in other locations. Young children (age 2-5) were very happy with the educational play items (such as the musical chimes) as well as the imaginative play items (such as the steering wheel). The small play house under the ramp was very successful as it represented a safe and quite space which is inside the playground but away from the crowd and the parents, its scale also represents an attraction for children as it suggests a space that is designed only for them and not for adults. Planting activities were organized to finalize the project, where children learned and enjoyed planting, while leaving their own contribution to the playground. 


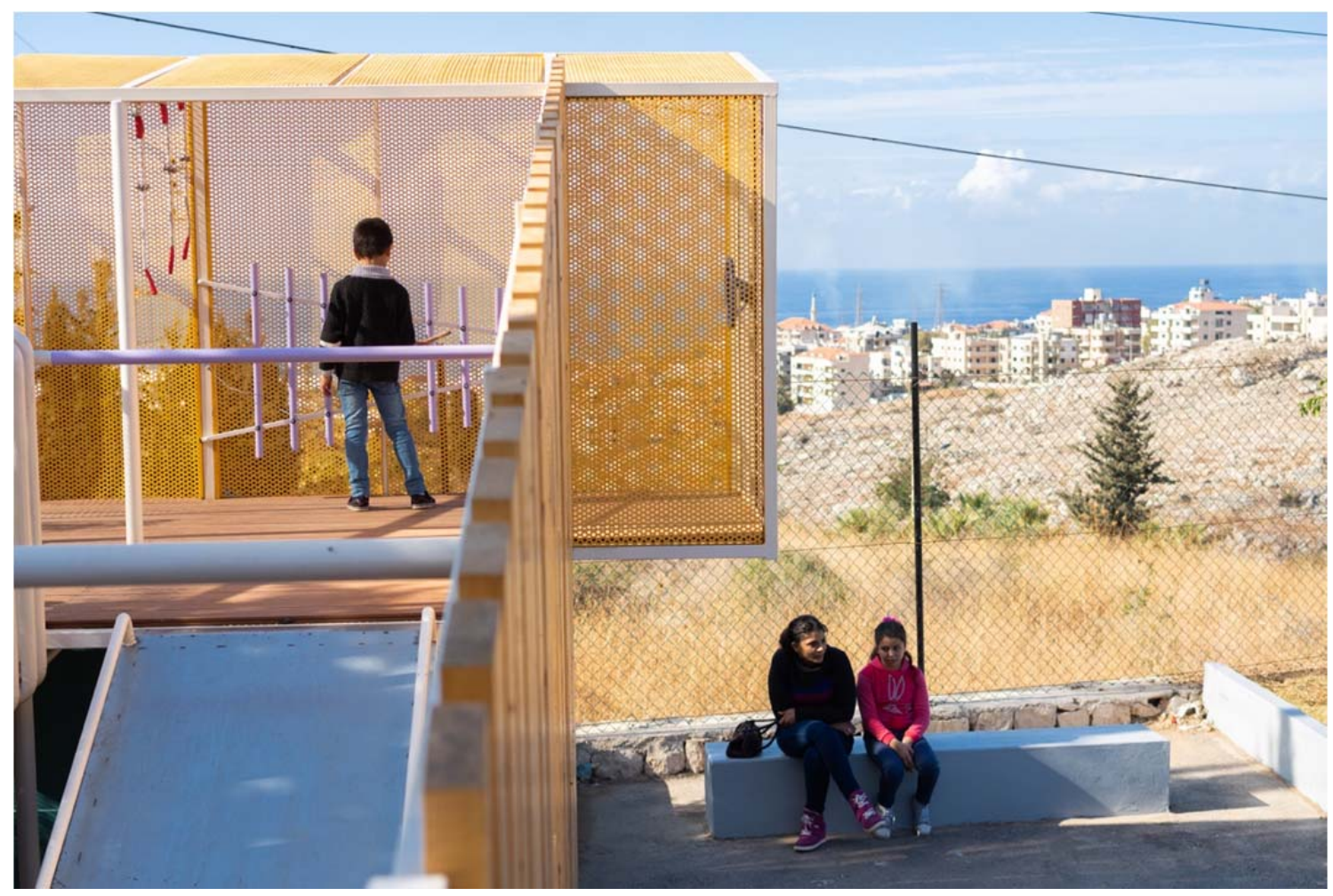

Figure 20. A young boy plays the xylophone while his mother and sister rest, Barja, 2019

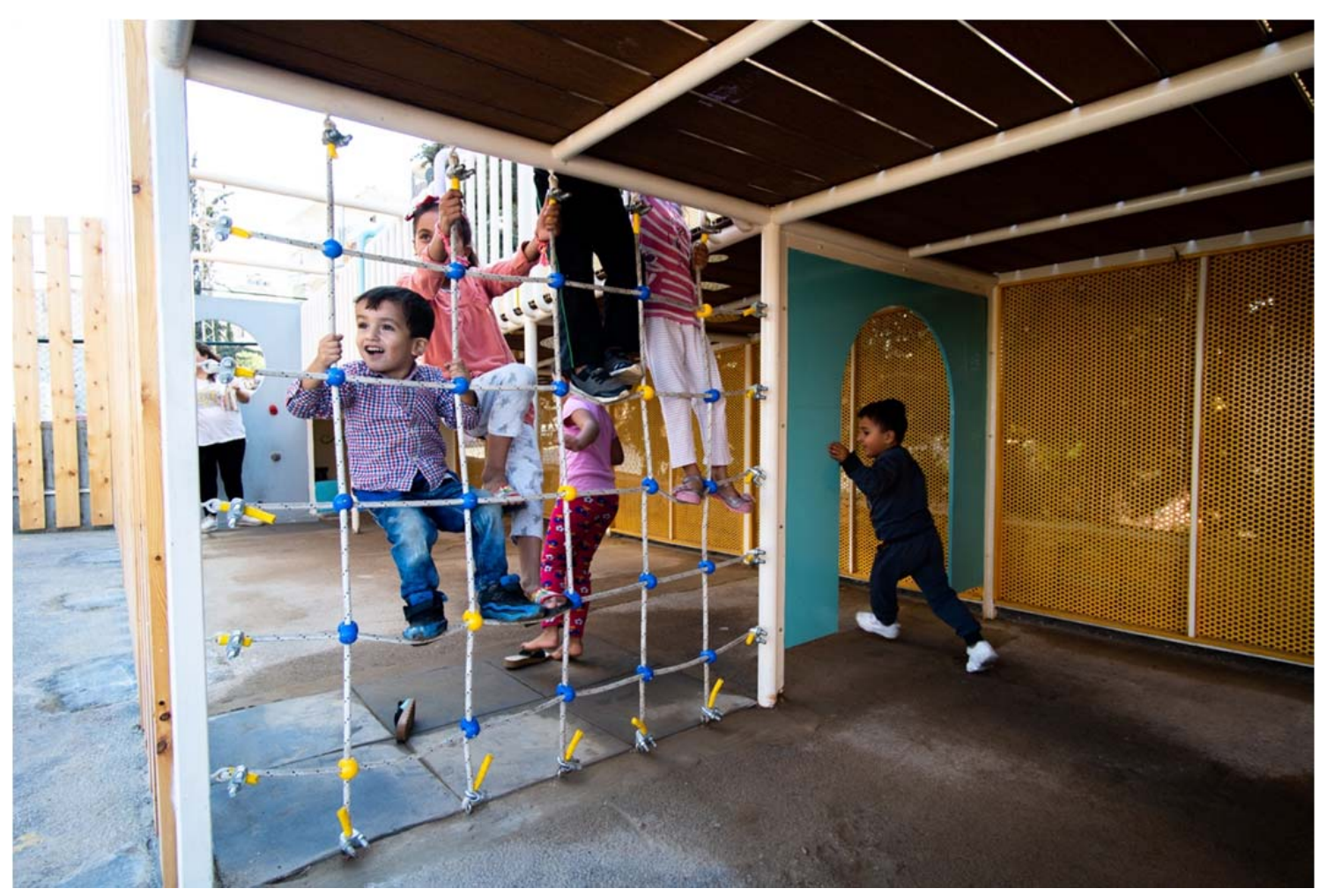

Figure 2I. Children racing to climb up the climbing net, Barja, 2019 


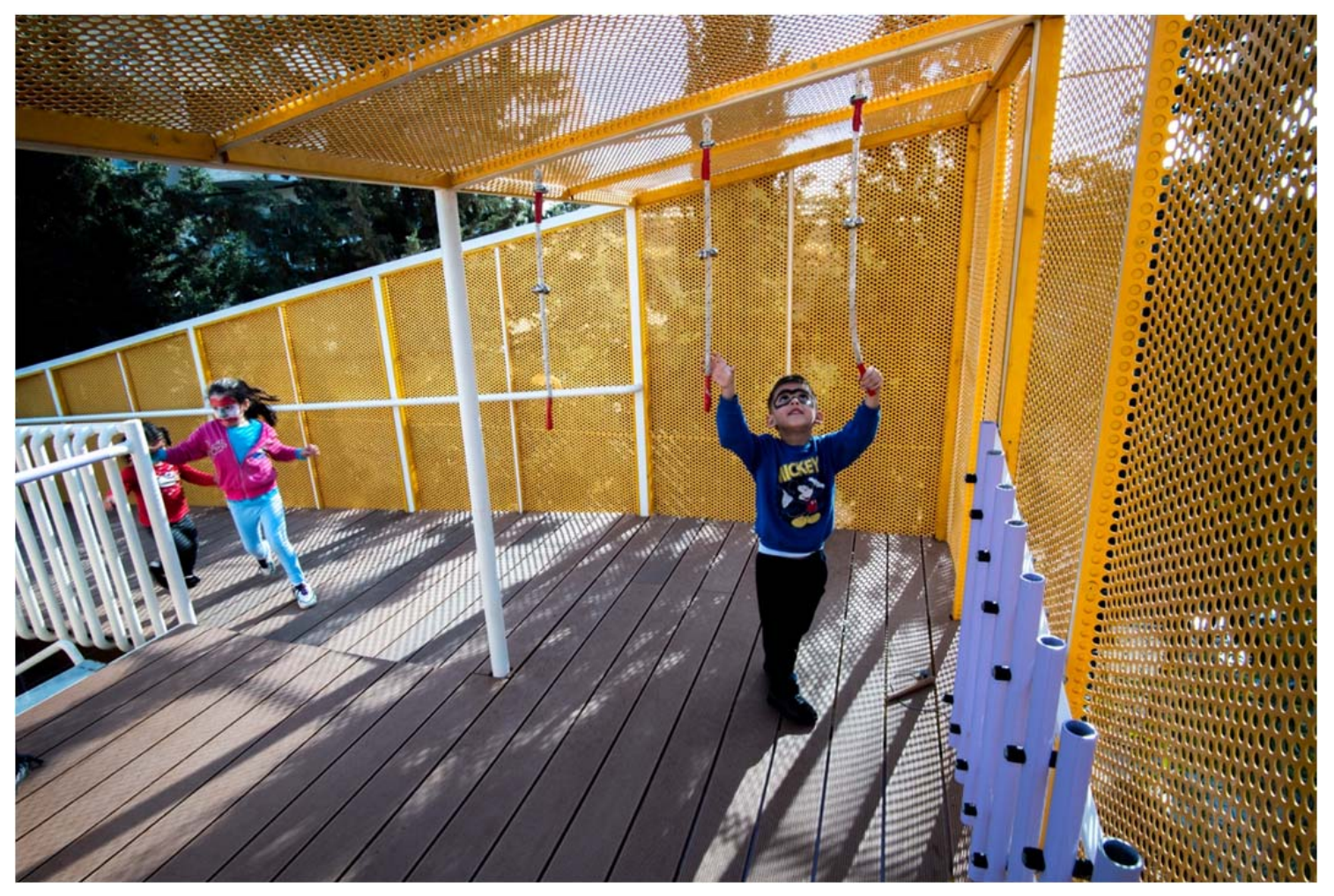

Figure 22. Children racing to climb up the climbing net, Barja, 2019

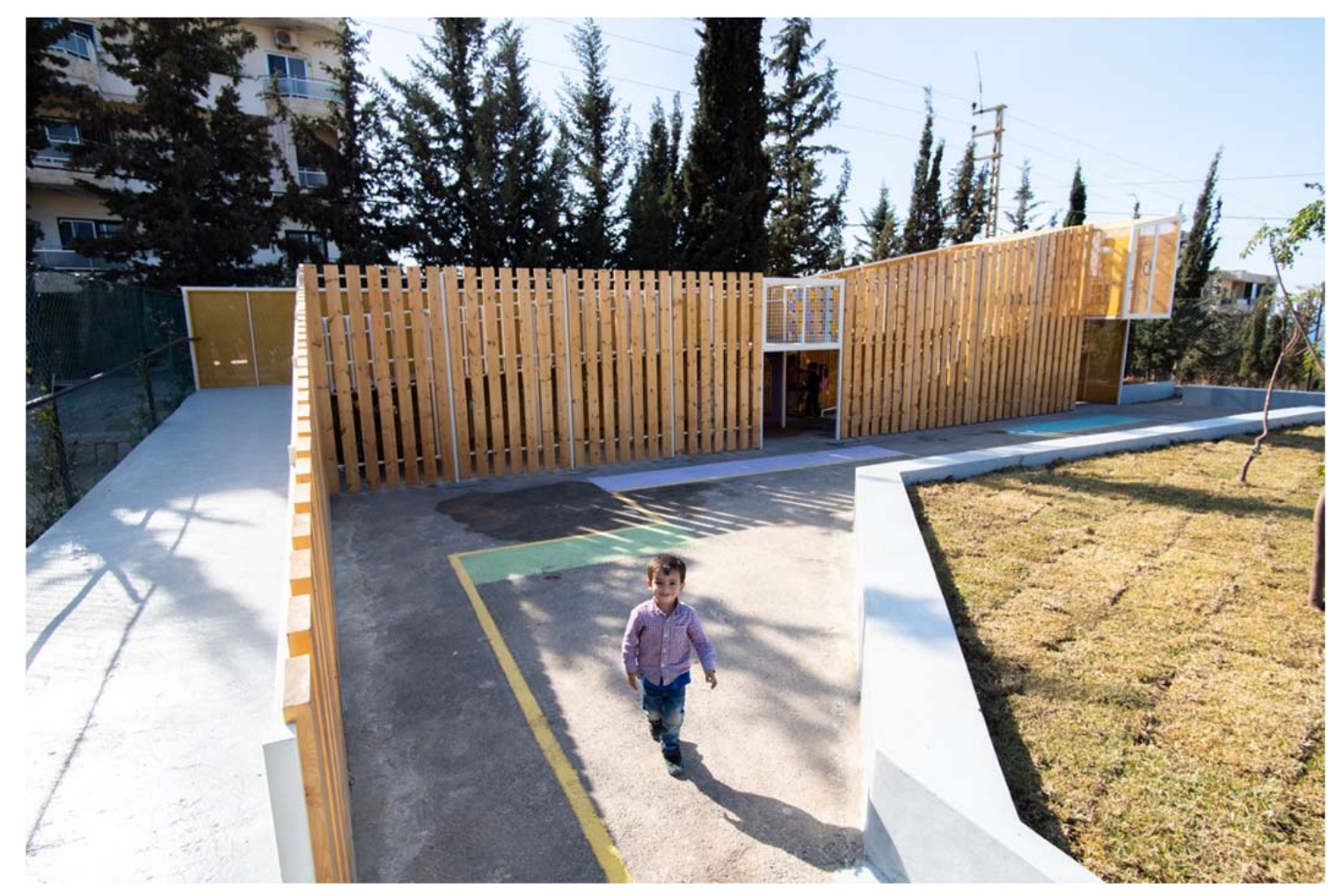

Figure 22. A compact playground design allowing different types of inclusive play, Barja, 2019

238 | The Journal of Public Space, 5(I), 2020 | ISSN 2206-9658

City Space Architecture / UN-Habitat 


\section{A street as a social hub}

Streets are important public spaces where different communities interact and engage in everyday life activities such as shopping or walking to get a taxi. With this project, CatalyticAction proves the potential of a road as a crucial public space for community cohesion. CA has been working in refugee hosting cities of the Bekaa valley in Lebanon since its initial activities on the ground, in 2014. In particular, they have worked in Bar Elias, central Bekaa since their first pilot project Ibtasem. Over the course of 4 years they developed and nourished their local networks and understanding of this context. In 2018, they collaborated with the RELIEF centre, a centre for research and learning focused on inclusive growth and prosperity. As part of this research partnership, CA developed the Participatory Spatial Intervention (PSI) with professor Andrea Rigon from the Bartlett Development Planning Unit at UCL. This project was implemented in Bar Elias, Lebanon, which according to the UNHCR Interagency Coordination Sector, is one of the most vulnerable localities in Lebanon (UNHCR, 20I5) due to the high presence of refugees and vulnerable populations combined with the lack of access to basic needs and livelihoods opportunities.

The overall objective of the project was to reduce vulnerabilities and improve wellbeing through spatial interventions, and to do so through the active participation of the local community. Throughout the process new ways are tested through which residents (refugees and hosts) co-produce the city and help understand how wellbeing is constructed and negotiated and how resilience is formed, imagined and practiced. The interventions are located in different locations on the main entrance road in Bar Elias, Bekaa, Lebanon. The project was implemented in close collaboration and coordination with Bar Elias municipality, this was very key towards the success of the project and its maintenance in the future.

Bar Elias PSI was developed and brought to completion through an extensive participatory process. Local researchers (citizen scientists) were recruited following an open call disseminated amongst key local stakeholders. Seven local researchers were selected, they are men and women from Lebanese, displaced and refugee communities Lebanese, Syrians and Palestinians. Local researchers were trained throughout the different phases of the project on: social research, research methods, ethics and data, participatory research, design thinking and human-centred approaches, and public engagement. The process of working with the local communities on how to research their built environment was a very enriching experience. Over the course of a year, local researchers were able to look at their town differently, questioning matters that in the past they took for granted. For some, this participatory approach represented the first opportunity of dialogue between the different nationalities living in Bar Elias, to produce a shared vision and a place for all of them.

Local researchers played a major role in a Development Planning Unit summerLab workshop "Public realm and spaces of refuge", in which they worked together with local and International participants and experts to investigate public spaces in Bar Elias. This workshop was an important step to help PSI team to identify the space of intervention for the activities of PSI. After visiting and investigating several public spaces, the identified space for the PSI was the entrance road of Bar Elias, one of the few public spaces of great importance to the city and used by most residents and visitors of Bar Elias from various nationalities. 


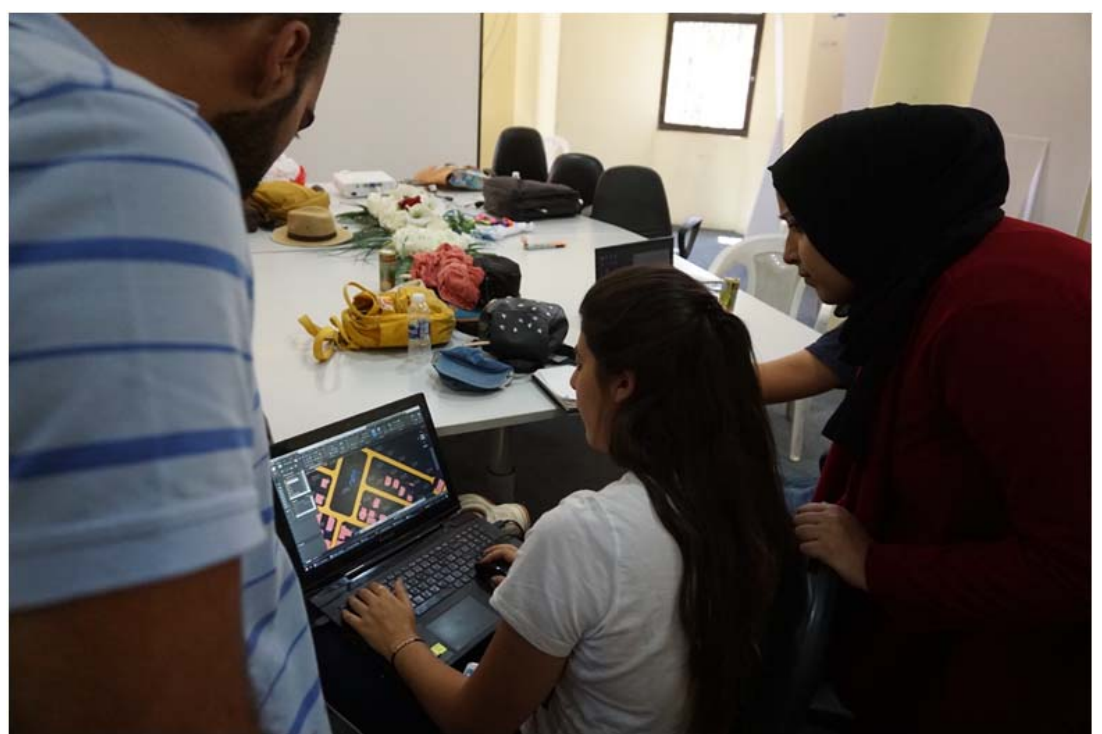

Figure 23. Local researchers and an architecture student from Birmingham discussing their intervention, Bar Elias, 2018

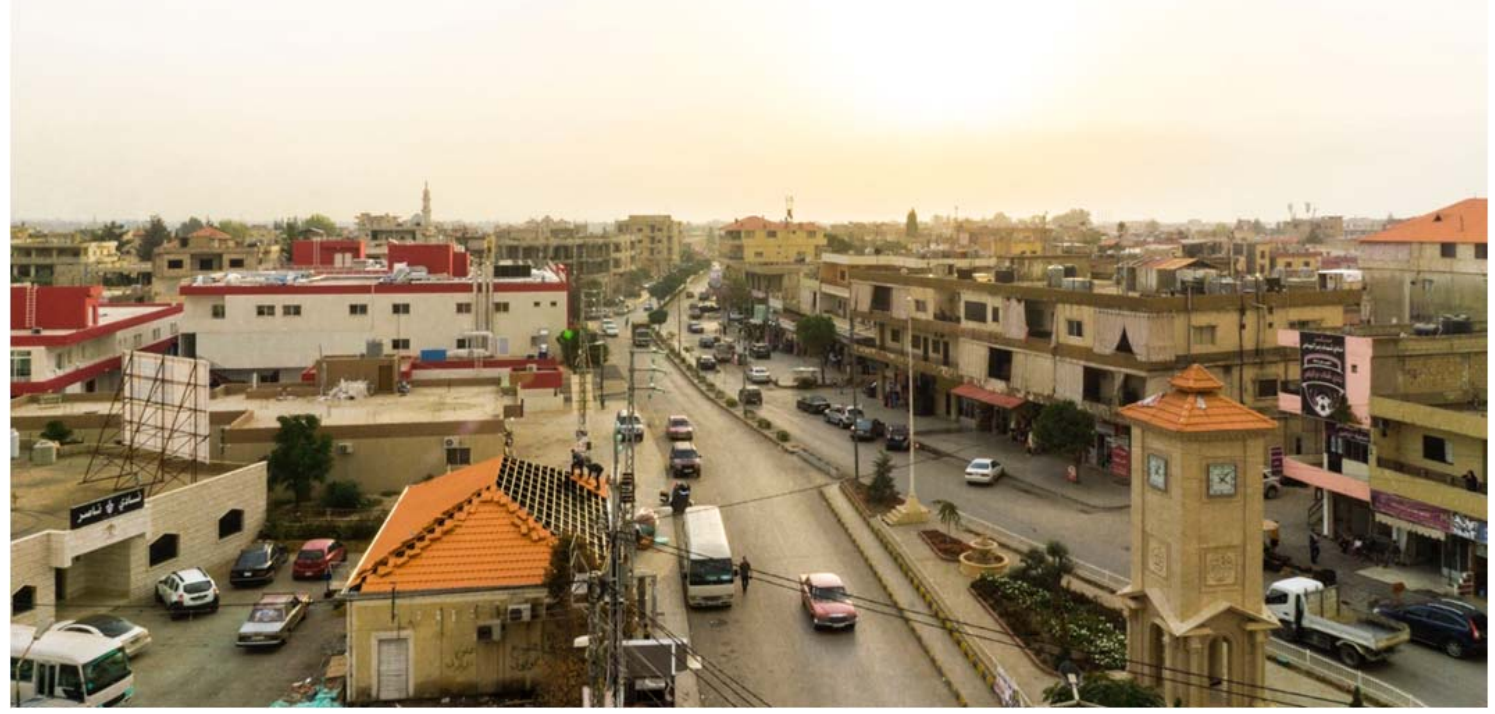

Figure 24. Bar Elias entrance road, Bar Elias, 2018

After identifying the space, an extensive participatory planning workshop was conducted in Bar Elias where local researchers participated as well as 12 local participants from different nationalities and age groups. A Syrian woman stated that the workshop was opportunity for Syrians to give back to society so that they are not perceived as only 
exploiting their host. A Lebanese man participant added that "there is no trust in society between people, no respect for the elderly", he expressed the need for a committee that brings people together, "the society is disintegrated, an old saying /story says that in life 3 things are important: chance, serendipity, learning. It is the good chance that brought us together, we shouldn't waste this unique opportunity." The workshop aimed at identifying the issues that the spatial intervention should address.

The focus of the workshop was not about producing solutions but rather thinking what could the solution be. Different research methods were used: observation, participatory mapping and semi-structured interviews. It was important that in each method used to make sure that different groups of participants were involved: men and women, children, adults, elderly, passers' by, residents, shop owners, workers, street venders, persons with different abilities, different nationalities and occupations.

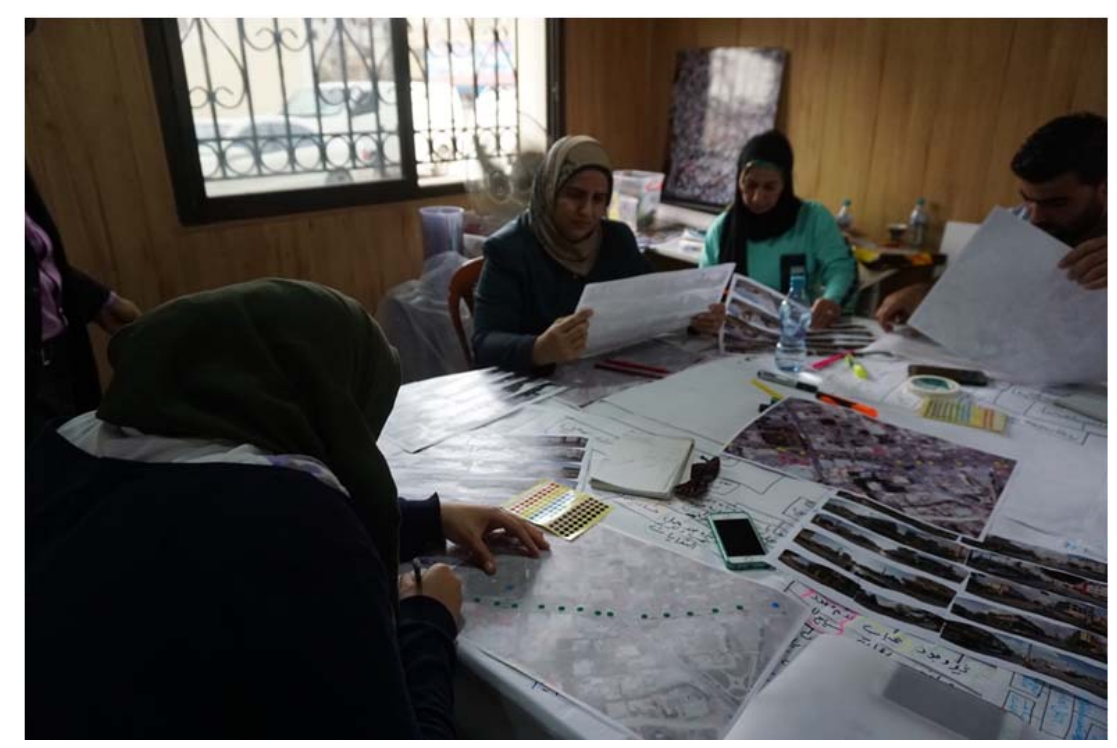

Figure 25. Workshop participants design their street interventions, Bar Elias, 2018

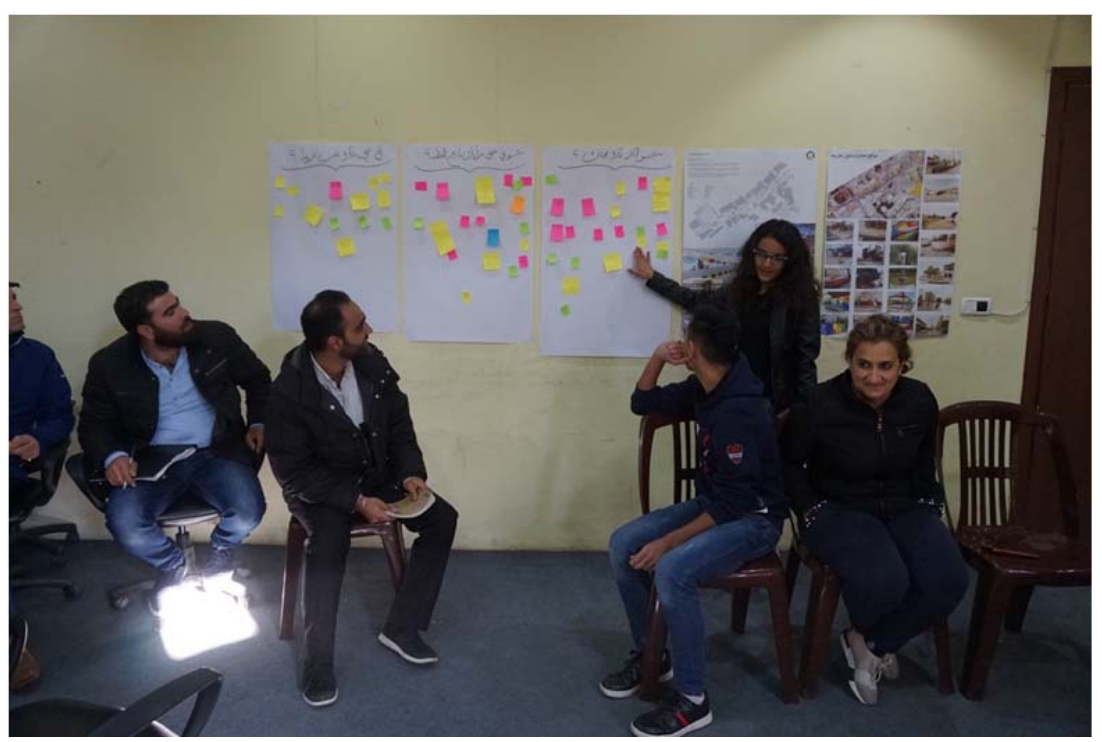

Figure 26. Final design consultation, Bar Elias, 2018 
Participants concluded that safety, accessibility, leisure, and safe play spaces for children were key issues. The design was therefore developed to respond to these issues. A public design consultation was also conducted to get further feedback from the local community on the proposed ideas. This was developed into a final design, the municipality approved all the interventions design, the mayor was particularly keen on the new bench and shading area in front of the polyclinic and how this whole project will give a good appearance to Bar Elias's entrance. CA negotiated different conditions of implementation that required full cooperation of the municipality.

The last phase of the project was the community engaged construction, during which CA with the support of local researchers outreached to the needed subcontractors in Bar Elias, the main construction team was formed of: a Palestinian concrete foreman who runs the business with his family, a Syrian welder whose shop is located in Bar Elias and lives in the nearby town of Ghazze, a Lebanese carpenter who was born and lives in Bar Elias with his family and a Syrian gardener who lives in the nearby town of Ghazze. I5 general construction labourers were Syrians living in Bar Elias, assisted in various activities of construction. Adding to this, 7 women from Bar Elias (2 Palestinians, 3 Syrians, 2 Lebanese) assisted in various activities of construction. Local community members, including children, also joined for different implementation activities such as painting the mural, benches and floor games.

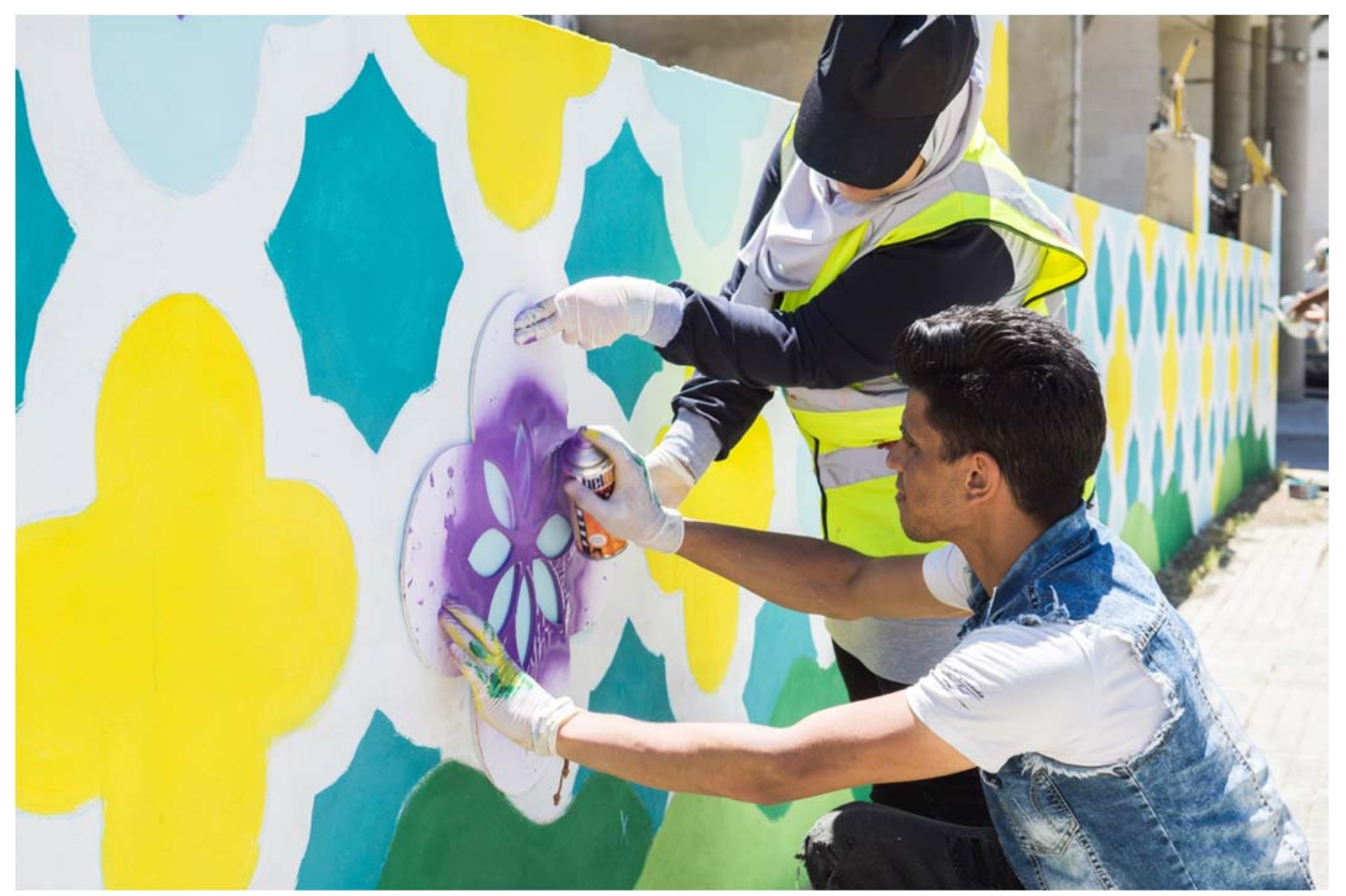

Figure 27. Local researchers participate in the mural painting, Bar Elias, 2019

The implementation took place during the month May 2019 coinciding with the holy month of Ramadan. From the Clock Tower to the main road's intersection with the Beirut-Damascus Highway, the spatial interventions were scattered in a harmonious 
manner. The timeline of the project was structured daily to include construction tasks and community activities. Four members of CA team were leading the implementation phase, present daily to ensure supervision, daily coordination with various subcontractors, with the municipality and other key stakeholders, as well as conducting community engaged activities. For example, collecting and reusing plastics to form the smaller shade structures, painting the benches and painting a mural. The mural that transformed a previously rough wall into a colourful wall at the entrance of the road.

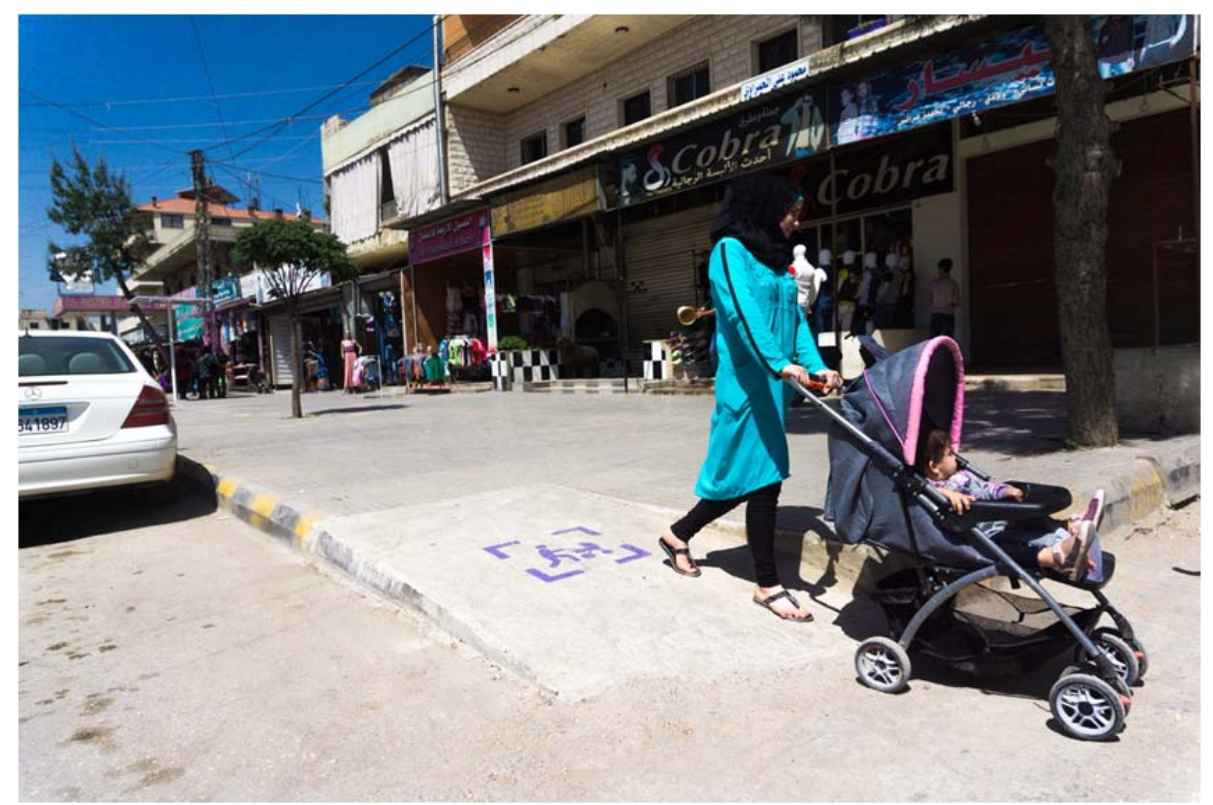

Figure 28. Access ramps created along all the sidewalks, Bar Elias, 2019

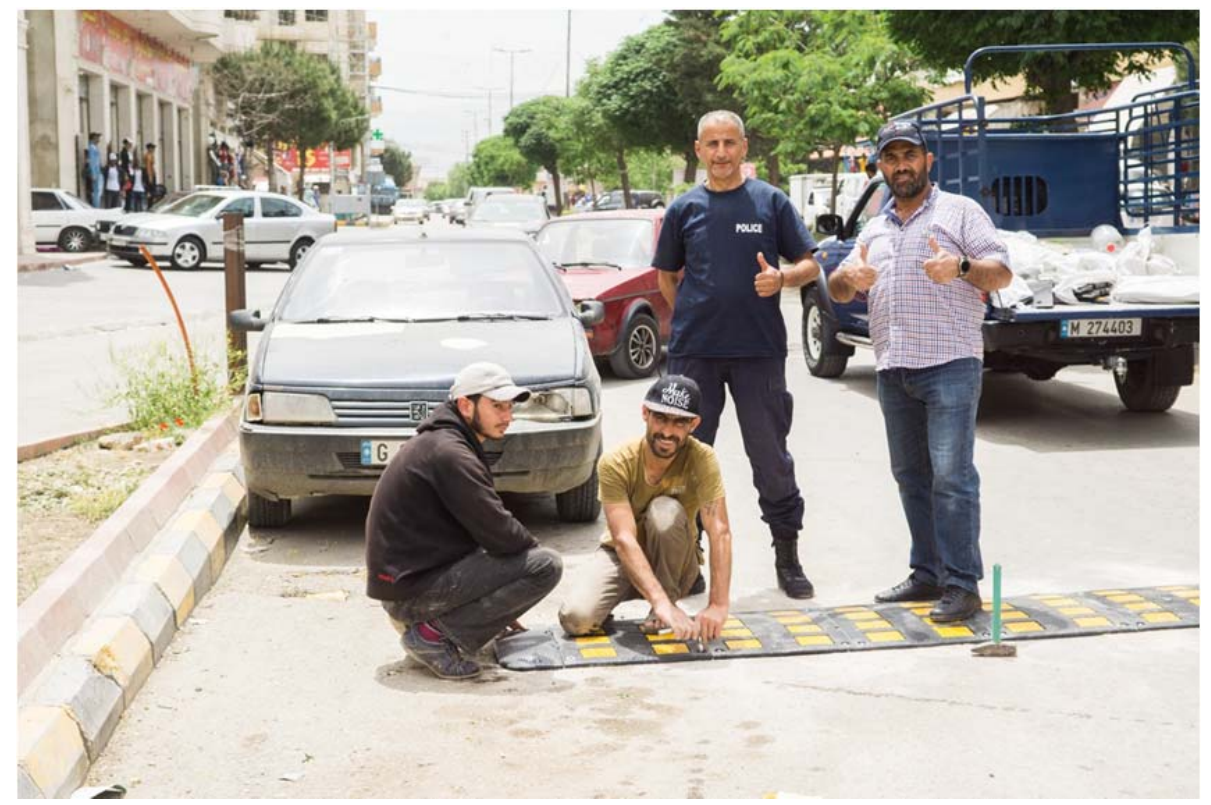

Figure 29. The municipality installing the speed humps together with one of the local researchers, Bar Elias, 2019 
Placemaking in Lebanese Cities Hosting Displaced Communities

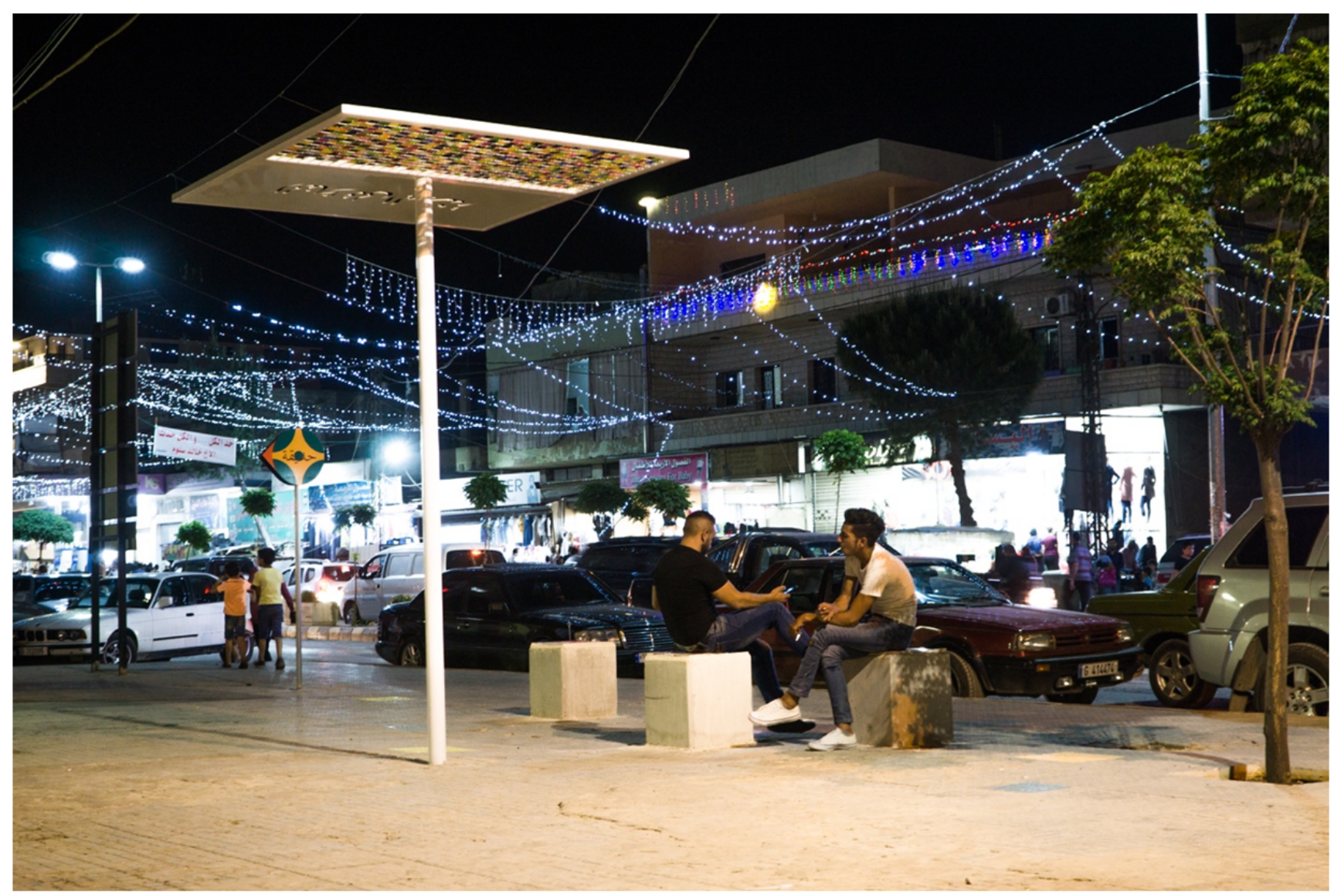

Figure 30. People enjoying the single seats at night, Bar Elias, 2019 
Joana Dabaj, Riccardo Luca Conti

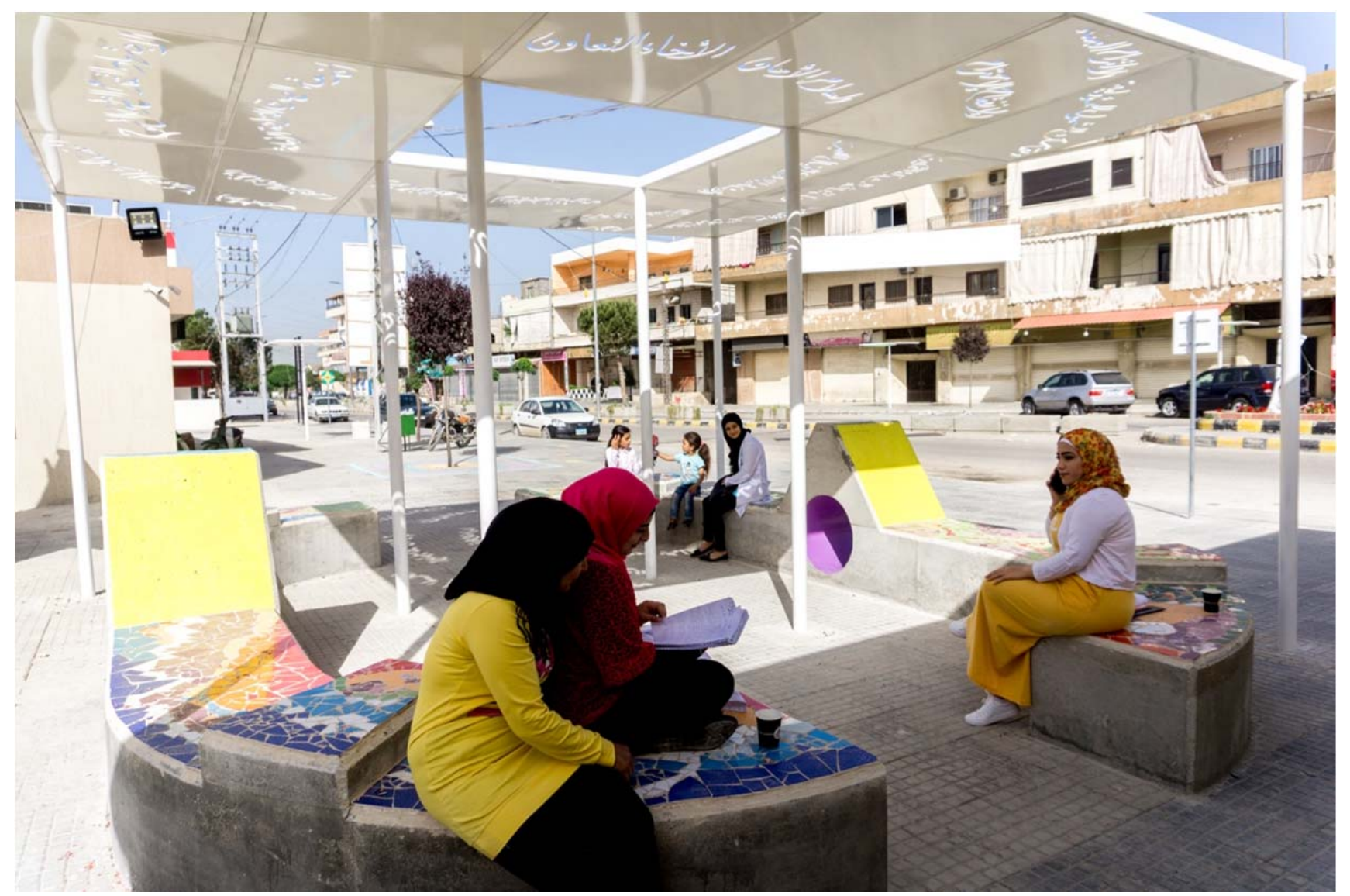

Figure 3I. The main shade and seating area in front of the polyclinic, Bar Elias, 2019 
An important aspect of the intervention was the joint learning, as well as sharing skills. The intervention has built the capacity of the local researchers and other residents to analyse problems, has encouraged other members of the community to participate in this work, think about diverse identities, and negotiate collective solutions. This project has led to the creation of a social infrastructure which is a public good for the entire city. The PSI in Bar Elias acted as a catalyst showing the potential of small participatory interventions; as the project resumed the polyclinic located on the road continued the intervention with their desired additions of benches, planters and pavement. The main shade and seating area became a landmark for the town, being used for public events and celebrations such as the prophet's birthday and Eid festivities. Adding to this, with this project process from inception to implementation women and elderly felt empowered voicing their own ideas and opinions, in a cultural context where their role is usually limited within their house. A Syrian woman realized with this project that she has a lot to say, she is not just a housewife with children, not just a mother with a role at home but she could give back to society and be part of it, "I am important, someone is interested in hearing what I have to say".

\section{Conclusion}

With the presented projects CatalyticAction shows the evolvement of their placemaking approach in Lebanese cities hosting displaced communities. The impact of this approach is multifaceted, impacting: the diverse communities and stakeholders who participate in its process; all other users of the places created; and neighboring communities who witness and inspire from the positive change placemaking brings. One of the key impacts is changing mind-sets in such challenging contexts, where with placemaking, displaced communities are not passive receivers but rather active agents who want to give back a lasting positive change within their host communities, and where local stakeholders such as local municipalities learn the value of engaging with their residents in decision making. It is crucial to note that with participatory approaches a lot of challenges are faced, in each project the challenges are different and relate to its context. Throughout their various projects, CA learned that partnership, context specificity and dialogue are key elements to overcome challenges and ensure a successful placemaking project. In Lebanon, the small country with a unique history of displacement and socio-cultural differences, placemaking becomes crucial for a prosperous future where community cohesion and integration allow, most importantly, children to grow in a safe environment. 